\title{
Using genetics to uncouple higher adiposity from its adverse metabolic effects and understand its role in metabolic and non-metabolic disease.
}

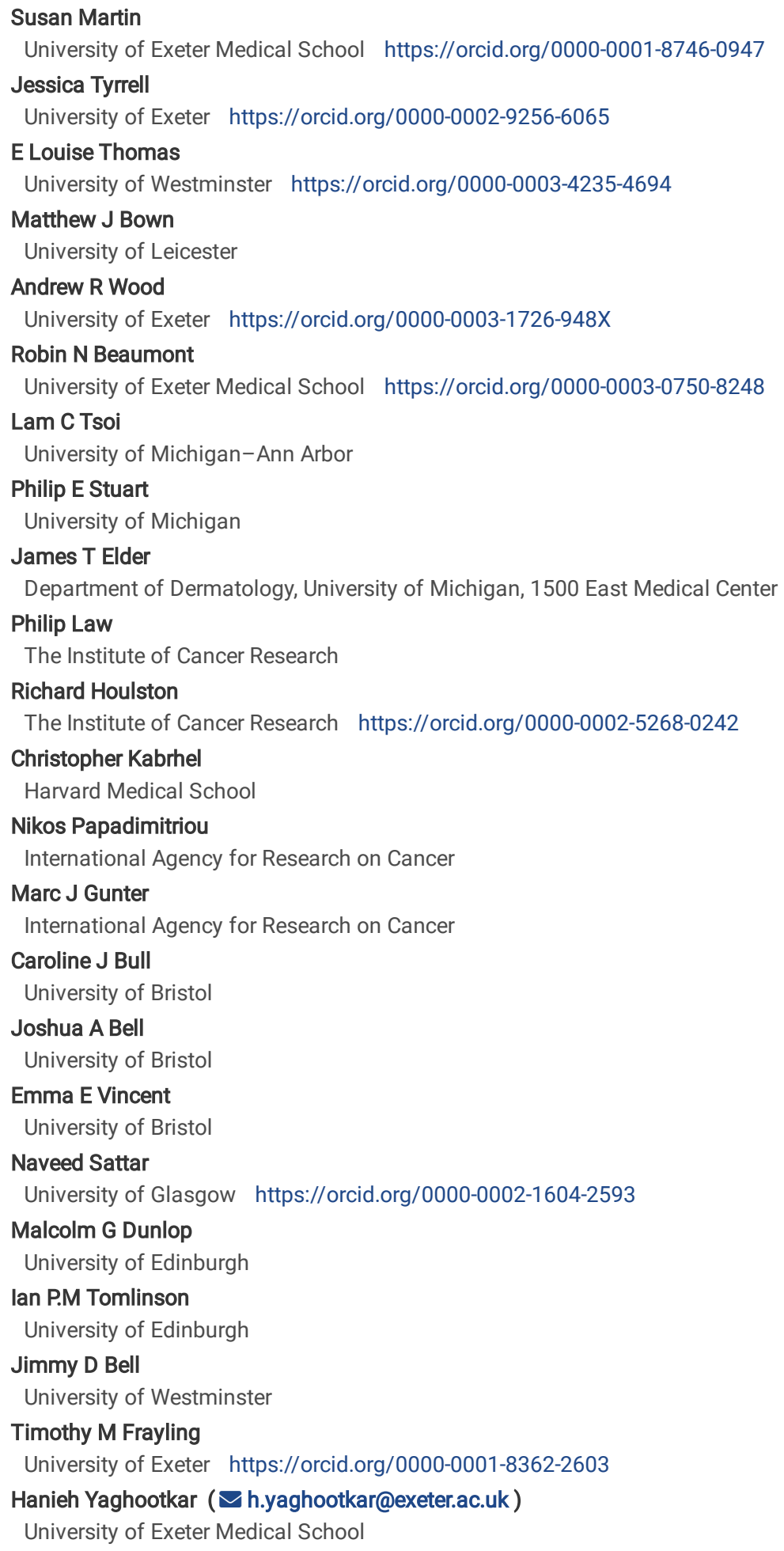

Keywords: Mendelian randomization, obesity, favourable adiposity, cardiovascular disease, cancer 
Posted Date: July 22nd, 2021

DOI: https://doi.org/10.21203/rs.3.rs-537397/v2

License: @ (i) This work is licensed under a Creative Commons Attribution 4.0 International License. Read Full License 


\section{Abstract}

To understand the consequences of higher adiposity uncoupled from its adverse metabolic effects, we selected 37 diseases associated with obesity and genetic variants associated with different aspects of excess weight including metabolically "favourable adiposity" (FA) and "unfavourable adiposity" (UFA). Mendelian randomisation (MR) identified two sets of diseases. First, 12 conditions where the metabolic effect of higher adiposity is the likely primary cause of the disease. Here MR with the FA and UFA genetics showed opposing effects on risk of disease, including colorectal and ovarian cancer, and gout. Second, 7 conditions where the non-metabolic effects of excess weight (e.g. mechanical effect) is likely a cause. Here MR with the FA genetics, despite leading to lower metabolic risk, and MR with the UFA genetics, were both associated with higher disease risk, including osteoarthritis and venous thromboembolism. Individuals with high BMI are at higher risk of some diseases despite being relatively metabolically healthy.

\section{Introduction}

Obesity is associated with a higher risk of many diseases, notably metabolic conditions such as type 2 diabetes, but many individuals are often relatively metabolically healthy compared to others of similar body mass index (BMI). Whilst these metabolically healthier individuals may be at lower risk of some obesity-related conditions, they may be at risk of conditions that are linked to other aspects of obesity, such as the load-bearing effects. The burden of obesity on individuals and health care systems is very large, and in the absence of a widely applicable, sustainable treatment or effective public health measures, it is important to understand the disease consequences of obesity, and how they may be best alleviated, in more detail.

To better understand the disease consequences of obesity, many previous studies have used the approach of Mendelian randomisation (MR) ${ }^{1}$. These studies used common genetic variants robustly associated with BMI as proxies for adiposity to assess the causal effects of higher BMI on many diseases. MR studies have provided strong evidence that higher BMI leads to osteoarthritis ${ }^{2}$, colorectal cancer ${ }^{3-5}$, and psoriasis ${ }^{6}$, as well as metabolic conditions such as type 2 diabetes, cardiovascular disease ${ }^{7}$ and heart failure ${ }^{8-10}$. Other MR studies indicate that higher BMI may lead to lower risk of some diseases, including postmenopausal breast cancer ${ }^{11}$ and Parkinson's disease ${ }^{12}$.

Obesity is heterogeneous - for example, for a given BMI, people vary widely in their amount of fat versus fat free mass, predominantly muscle, and their distribution of fat, predominantly subcutaneous versus ectopic and upper versus lower body fat. Even when there is strong evidence of causality, obesity may lead to disease through a variety of mechanisms. Despite many MR studies testing the role of higher BMI in disease, few have attempted to separate and test the different mechanisms that could lead from obesity to disease. Some MR studies have investigated the effects of fat distribution, using genetic variants associated with waist-hip-ratio (WHR) adjusted for BMI and shown that adverse fat distribution (more upper body, less lower body) leads to higher risk of metabolic disease ${ }^{13}$, some cancers ${ }^{14}$ and gastro-oesophageal reflux disease ${ }^{15}$.

Previous studies have identified genetic variants associated with more specific measures of adiposity. For example, several studies have characterised variants associated with 'favourable adiposity' (FA) or reduced adipose storage capacity ${ }^{16-19}$ using a variety of approaches. Our approach used body fat percentage in addition to the metabolic biomarkers (HDL cholesterol (HDL), sex hormone-binding globulin (SHBG), triglycerides, ALT and AST) that have previously been used to clinically distinguish between monogenic obesity and lipodystrophy 20,21 , to find resembling polygenic phenotypes (Supplementary Table 1). Collectively, FA genetic variants are associated with a favourable metabolic profile, higher subcutaneous fat but lower ectopic liver fat ${ }^{16,22}$, resembling a polygenic phenotype opposite to lipodystrophy ${ }^{20}$. In contrast the unfavourable adiposity (UFA) variants are associated with higher fat in subcutaneous and visceral adipose tissue, and higher ectopic liver and pancreatic fat ${ }^{16,22}$, resembling monogenic obesity (Supplementary Table 1 ). We recently used the genetic variants associated with FA and UFA to perform MR studies with six metabolic conditions ${ }^{22}$. These MR studies showed that FA and UFA have opposite effects on metabolic conditions - while both FA and UFA were associated with higher adiposity, FA was causally associated with lower risk of type 2 diabetes, heart disease, hypertension, stroke, polycystic ovary syndrome and non-alcoholic fatty liver disease. In contrast, as expected, UFA was associated with higher risk of these conditions. These results confirmed the ability of the two sets of adiposity variants to partially separate out the metabolic from the non-metabolic effects of higher adiposity.

In this study, we aimed to investigate the effects of separate components to higher adiposity on risk of additional metabolic diseases and many nonmetabolic diseases. We used genetic variants associated with BMI, body fat percentage, FA and UFA, to understand the components of higher adiposity that are the predominant causes of disease risk. We did so as the findings may give guidance on some obesity-related risks which are not dependent on metabolic consequences, thereby guiding appropriate medical care.

\section{Method}

\section{Study design}


An overview of our approach is shown in Supplementary Figure 1. First, we identified diseases by performing a literature search of studies that had used Mendelian randomisation to assess the consequences of BMI on outcome phenotypes. We used the search terms "BMI and Mendelian randomisation" and "BMI and Mendelian randomization". We identified 37 diseases associated with BMI and for which MR studies had previously been performed (Supplementary Table 2). We included all diseases regardless of the MR result in the published study. Second, we reperformed MR studies using BMI as an exposure. Third, for those diseases where MR indicated higher BMI was causal, we tested the effects of body fat percentage to confirm that the causal effect was due to fat mass rather than fat free mass. Fourth, for diseases where MR suggested the BMI effect was due to excess adiposity, we used genetic variants more specific to the metabolic and non-metabolic components of higher adiposity to help understand the extent to which these factors influence disease.

\section{Disease outcomes}

We used summary statistics from existing genome-wide association studies (GWAS). Among the 37 identified diseases, 25 had summary GWAS data available from both a published GWAS consortium and FinnGen ${ }^{23}$, and 12 diseases had GWAS summary data available in FinnGen only, while 31 were available in the UK Biobank. No GWAS data were available for Barrett's oesophagus, but we included gastro-oesophageal reflux. The definition of cases and controls in published GWAS, FinnGen and UK Biobank are available in Supplementary Table 3a-c

\section{GWAS of UK Biobank traits}

The UK Biobank has been described in detail elsewhere ${ }^{24}$ but in summary, it includes $>500,000$ individuals aged $37-73$ years ( $99.5 \%$ were between 40 and 69 years of age) recruited between 2006 and 2010 from across the UK. All participants provided informed written consent and the National Research Ethics Service Committee North West-Haydock approved the study. All procedures in the UK Biobank study were conducted in accordance to the World Medical Association declaration of Helsinki ethical principles for medical research. The characteristics of the study and measures and disease outcomes we used are described in Supplementary Table 3c. For our GWAS studies, we used a linear mixed model implemented in BOLT-LMM to account for population structure and relatedness. We used age, sex, genotyping platform, study centre, and the first five principal components as covariates in the model.

\section{Genetic variants}

We used four sets of genetic variants as proxies of four exposures (Supplementary Table 4):

BMI. In the broadest category, we used a set of 73 variants independently associated with $\mathrm{BMI}$ at genome-wide significance $\left(\mathrm{P}<5 \times 10^{-8}\right)$. These variants were identified in the GIANT consortium of up to 339,224 individuals of European ancestry 25 .

Body fat percentage. We identified 696 variants by performing a GWAS in the UK Biobank. We used bio-impedance measures of body fat \% taken by the Tanita BC-418MA body composition analyser in 442,278 individuals of European ancestry. We used a linear mixed model implemented in BOLT-LMM ${ }^{26}$ to account for population structure and relatedness. We used age, sex, genotyping platform, study centre, and the first five principal components as covariates in the model.

The BMI and body fat percentage variants were partially overlapping ( $n=5$ variants) but we used exposure trait specific weights for each variant.

Favourable adiposity (FA) variants. There are $36 \mathrm{FA}$ variants ${ }^{22}$. These variants were identified in two steps. First, they were associated $\left(\right.$ at $\left.\mathrm{P}<5 \times 10^{-8}\right)$ with body fat percentage and a composite metabolic phenotype consisting of body fat percentage, HDL-cholesterol, triglycerides, SHBG, alanine transaminase and aspartate transaminase. The five circulating markers were selected because they are established markers that separate different monogenic forms of altered adiposity - monogenic obesity and lipodystrophy. Second, in a k-means clustering approach (a hard clustering approach) 22 they formed a cluster of variants that were collectively associated with higher HDL-cholesterol, higher SHBG, and lower triglycerides and liver enzymes - paradoxical to the observational associations between higher adiposity and these measures.

Unfavourable adiposity (UFA) variants. There are 38 UFA variants ${ }^{22}$. These variants were identified in two steps. First, they were associated (at $\mathrm{P}<5 \times 10^{-8}$ ) with body fat percentage and a composite metabolic phenotype consisting of body fat percentage, HDL-cholesterol, triglycerides, SHBG, alanine transaminase and aspartate transaminase. Second, in our k-means clustering approach ${ }^{22}$ they formed a cluster of variants that were collectively associated with lower HDLcholesterol, lower SHBG, and higher triglycerides and liver enzymes. Variants that were associated with body fat \% but did not cluster together with the FA or UFA were not used further. 


\section{Mendelian randomisation}

We investigated the causal associations between the four exposures (BMI, body fat percentage, FA and UFA) and 37 disease outcomes by performing twosample MR analysis ${ }^{27}$. We used the inverse-variance weighted (IVW) approach as our main analysis, and MR-Egger and weighted median as sensitivity analyses in order to detect and partially account for unidentified pleiotropy of our genetic instruments. For BMI, we used effect size estimates from the GWAS of $\mathrm{BMI}^{25}$ and for body fat percentage, FA and UFA, we used effect size estimates from the GWAS of body fat percentage (442,278 European ancestry individuals from the UK Biobank study) ${ }^{16}$.

To estimate the effects of variants on our outcome diseases, we used two main sources of data: FinnGen GWAS summary results and published GWAS of the same diseases (Supplementary Table 3a-b). We performed MR within each data source and then meta-analysed the results across the two datasets using a random-effects model with the R package metafor ${ }^{28}$, where the data was available in both. For one published GWAS (the GECCO consortium), we only had information for FA and UFA variants.

To provide further MR evidence we used a third source of disease data - disease status in the UK Biobank (Supplementary Table 3c). We ran the same models but did not meta-analyse with published GWAS and FinnGen because most of the body fat percentage, FA and UFA variants were identified in the UK Biobank.

We obtained heterogeneity Q statistics for each inverse-variance weighted MR and MR-Egger, and $R$ statistics for each MR-Egger analysis using the MendelianRandomization $\mathrm{R}$ package ${ }^{29}$. All statistical analyses were conducted using $\mathrm{R}$ software ${ }^{30}$.

Given the number of tests performed, we used a Benjamini-Hochberg false discovery rate (FDR) procedure and an FDR of 0.1 to define meaningful results for each of the 4 exposures ${ }^{31}$.

\section{Data availability}

Published GWAS data are available from the relevant publication or upon request from the corresponding authors (Supplementary Table 3a). FinnGen data is available at: https://finngen.gitbook.io/documentation/. UK Biobank data is available upon request at: https://www.ukbiobank.ac.uk.

\section{Results}

We identified 37 diseases as associated with obesity and for which MR studies had previously been performed. Of these 37 , five metabolic conditions were part of our previous study that validated the use of FA and UFA genetic variants as a way of partially separating the metabolic from non-metabolic components of higher adiposity ${ }^{22}$. Once we had tested BMI and body fat percentage, we further characterised the likely causal component of higher adiposity using FA and UFA variants as follows (Supplementary Figure 1, Step 5):

i) Diseases with evidence that the metabolic effect of higher adiposity is causal. Here MR using the UFA genetic variants indicated that higher adiposity with its adverse metabolic consequences was causal to disease, whilst MR using the FA genetic variants indicated that higher adiposity with favourable metabolic effects was protective (at FDR 0.1).

ii) Diseases with evidence that there is a non-metabolic causal effect (e.g. mechanical effect, psychological/adverse social effect). Here MR using the FA genetic variants indicated that higher adiposity without its adverse metabolic consequences was likely contributing to the disease, as well as the MR using the UFA genetic variants. 


\section{Cardiovascular and metabolic conditions}

Diseases in this category included coronary artery disease (CAD), peripheral artery disease, hypertension, stroke, heart failure, aneurysm, atrial fibrillation, venous thromboembolism, deep vein thrombosis, pulmonary embolism, type 2 diabetes, polycystic ovary syndrome and chronic kidney disease (Table 1 ). Five of these 13 conditions (CAD, hypertension, stroke, type 2 diabetes and polycystic ovary syndrome) were part of our previous study 22 . MR analysis provided evidence for a causal association between higher BMI and higher odds of eleven of these diseases, the exceptions being pulmonary embolism and aortic aneurysm. For each of these 11 diseases, our MR analysis using body fat percentage as the exposure indicated that the risk was due to excess adiposity.

When comparing the MR analyses for FA and UFA, our results provided evidence that the metabolic effect of higher adiposity is contributing causally to coronary artery disease, peripheral artery disease, hypertension, stroke and type 2 diabetes, and is the predominant cause of the link between BMI and polycystic ovary syndrome. In addition, our results provided evidence that the metabolic effect of higher adiposity is the predominate cause of the link between higher BMI and heart failure and atrial fibrillation. For example, the MR analyses indicated the opposite direction of effects of FA and UFA with peripheral artery disease; a 1-SD higher genetically-instrumented FA was associated with $0.20[0.11,0.38]$ lower odds of peripheral artery disease, while a 1-SD higher genetically-instrumented UFA was associated with 3.31 [2.09, 5.24] higher odds of peripheral artery disease. In contrast, the MR analysis provided evidence that a non-metabolic effect of higher adiposity is likely contributing to venous thromboembolism and deep vein thrombosis. For example, the MR analyses indicated the same direction of effects of FA and UFA with venous thromboembolism; a 1-SD higher genetically-instrumented FA was associated with 2.52 [1.82, 3.47] higher odds of venous thromboembolism, and a 1-SD higher genetically-instrumented UFA was associated with 1.63 [1.25, 2.13] higher odds of venous thromboembolism (Figure 1a-c, Table 1). For stroke, our results were consistent when using sub-types of the condition (Supplementary Figure 2a, Supplementary Table 6).

\section{Musculoskeletal system}

Diseases in this category included gout, osteoarthritis, rheumatoid arthritis and osteoporosis. MR analysis provided evidence for a causal association between higher BMI and higher odds of gout, osteoarthritis and rheumatoid arthritis. Our MR analysis using body fat percentage as the exposure, indicated that for all three diseases the risk was due to excess adiposity.

When comparing the MR analyses for FA and UFA our results provided evidence that the metabolic effect of higher adiposity is causing gout. For example, the MR analyses indicated opposing effects of FA and UFA with gout, with a 1-SD genetically-instrumented FA associated with 0.44 [0.29, 0.68$]$ lower odds of gout, while a 1-SD genetically-instrumented UFA was associated with $2.49[1.88,3.29]$ higher odds of gout. In contrast, the MR analysis provided evidence that there is a likely non-metabolic effect of higher adiposity causing osteoarthritis and rheumatoid arthritis. For example, the MR analyses indicated the same direction of the effects of FA and UFA with osteoarthritis; a 1-SD higher genetically-instrumented FA was associated with 1.45 [1.19, 1.76] higher odds of osteoarthritis, and a 1-SD higher genetically-instrumented UFA was associated with $2.20[1.64,2.95]$ higher odds of osteoarthritis (Figure 1d, Table 1). For osteoarthritis, our results were consistent when using sub-types of the condition (Supplementary Figure 2b, Supplementary Table 6).

\section{Gastrointestinal system}

Diseases in this category included gastro-oesophageal reflux disease and cholelithiasis (gallstones). MR analysis provided evidence for a causal association between higher BMI and higher odds of both diseases. For both diseases, our MR analysis using body fat percentage as the exposure indicated that the risk was due to excess adiposity.

When comparing the MR analyses for FA and UFA our results suggested that the non-metabolic effect of higher adiposity is the predominant cause of the link between higher BMI and gallstones. For example, a 1-SD higher genetically-instrumented UFA was associated with 2.55 [1.88, 3.45] higher odds of gallstones and higher genetically-instrumented FA was associated with higher risk $(1.37[0.86,2.19])$ but with less conclusive evidence (p>0.05) (Figure 1e, Table 1). For gastro-oesophageal reflux disease, the results were less conclusive but the same direction and similar effect sizes suggested a likely non-metabolic effect (Figure 1e, Table 1).

\section{Nervous system}

Diseases in this category included depression, Parkinson's disease, multiple sclerosis and Alzheimer's disease. MR analysis provided no evidence (at $\mathrm{p}<0.05$ ) for a causal association between BMI and any of these diseases. For depression, our MR analysis indicated that excess adiposity was a risk factor (1.19 [1.11, 1.28]). 
When comparing the MR analyses for FA and UFA there was no conclusive evidence (at $p<0.05)$ of a non-metabolic or metabolic effect on depression, with both MR of UFA and FA directionally consistent with higher risk, but results were consistent with the null: higher FA $(1.20$ [0.98, 1.48] and higher UFA (1.02 $[0.81,1.30]$ ) (Figure 1f, Table 1).

\section{Integumentary system}

Diseases in this category included psoriasis. MR analysis provided evidence for a causal association between higher BMI and higher odds of psoriasis ( 1.62 $[1.20,2.19])$. Our MR analysis using body fat percentage as the exposure indicated that the risk was due to excess adiposity $(1.78$ [1.54, 2.05$])$.

When comparing the MR analyses for FA and UFA, our results suggested that the non-metabolic effect of higher adiposity is the likely predominant cause of the link between higher BMI and psoriasis. A 1-SD genetically-instrumented UFA was associated with a 2.11 [1.49, 2.99] higher odds of psoriasis and higher genetically-instrumented FA was associated with higher odds $(1.20[0.70,2.06])$ but this result was consistent with the null ( $p>0.05)($ Figure $1 \mathrm{~g}$, Table 1).

\section{Respiratory system}

The diseases in this category included adult-onset asthma. MR analysis provided evidence for a causal association between higher BMI and higher odds of adult-onset asthma: $1.25[1.03,1.52]$. Our MR analysis using body fat percentage as the exposure indicated that the risk was due to excess adiposity (1.43 $[1.25,1.63])$.

When comparing the MR analyses for FA and UFA, our results did not provide conclusive evidence for either a non-metabolic or metabolic effect. Whilst the MR analyses indicated the same direction of the effects of FA $(1.14[0.88,1.49])$ and UFA $(1.34[0.97,1.87])$ with higher odds of adult-onset asthma, these results included the null $(\mathrm{p}<0.05)$ (Figure $1 \mathrm{~h}$, Table 1$)$. Our results when using child-onset asthma are given in Supplementary Figure $2 \mathrm{c}$ and Supplementary Table 6.

\section{Cancer}

Diseases in this category included breast cancer, endometrial cancer, renal cancer, meningioma, prostate cancer, myeloma, pancreatic cancer, colorectal cancer, lung cancer, Barrett's oesophagus, ovarian cancer, and thyroid cancer. MR analysis provided evidence for a causal association between higher BMI and higher odds of endometrial $(1.82$ [1.26, 2.63]) and renal cancer (1.47 [1.12, 1.92]), and higher BMI and lower odds of breast cancer (0.60 [0.51, 0.70]). The MR evidence that excess adiposity was the predominant cause of the link between higher BMI and these three cancers was less clear than for other types of disease (Figure 1i-k, Table 1).

When comparing the MR analyses for FA and UFA our results did not provide consistent evidence for either a non-metabolic or a metabolic effect. We identified some evidence of a metabolic effect of higher adiposity with colorectal and ovarian cancer, with the MR of FA indicating lower odds of colorectal $(0.67[0.52,0.85])$ and ovarian $(0.35[0.18,0.70])$ cancers, but MR of UFA was consistent with the null $(p>0.05)$. For colorectal and ovarian cancer, our results were consistent when using sub-types of the conditions (Supplementary Figure 2d-f, Supplementary Table 6).

\section{Sensitivity analyses}

Out of a possible 82 total study-specific traits, weighted median MR results were directionally consistent with IVW analysis for 75 traits for BMI and 73 for body fat percentage, with 33 and 47 of these having $p<0.05$ respectively. For FA and UFA, where sub-type colorectal cancer data was available, the total number of traits was 87 , and 76 were directionally consistent for both exposures, with 22 and 39 having p<0.05 respectively. Meanwhile, MR-Egger results were directionally consistent with IVW for 71 traits for BMI and 70 for body fat percentage, with 25 and 38 of these having p<0.05 respectively. For FA and UFA, MR-Egger was directionally consistent for 60 and 67 traits, with 6 and 15 having $p<0.05$ respectively (Supplementary Table 6). Of the 31 diseases available in the UK Biobank, the IVW analysis of these were directionally consistent with the FinnGen and/or published GWAS analysis for $28,27,24$ and 27 traits for BMI, body fat percentage, FA and UFA, respectively (Supplementary Table 7). Of these, 18, 21, 9 and 16 had $p<0.05$ respectively.

\section{Discussion}

We used a genetic approach to understand the role of higher adiposity uncoupled from its adverse metabolic effects in mechanisms linking obesity to higher risk of disease. We first used MR to provide evidence that higher BMI was causally associated with 21 diseases, broadly consistent with those from previous 
studies. For the majority (17) of these diseases, our results indicated that the BMI effect was predominantly due to excess adiposity rather than a non-fat mass component to BMI. We then used a more specific approach to test the separate roles of higher adiposity with and without its adverse metabolic effects.

Understanding the reasons why obesity leads to disease is important in order to better advise health professionals and patients of health risks linked to obesity, whether or not they show metabolic derangements. Many previous studies have used an MR approach to support a causal role of higher BMI in disease but here we attempted to systematically test many conditions and the role of separate components of higher BMI. We discuss some of the more notable, and potentially clinically important, results below.

Cardio-metabolic diseases. Previous studies, including those using MR, have shown that higher BMI leads to many cardio-metabolic diseases ${ }^{32-34}$, but our results provide additional insight into the likely mechanisms. In addition to the previously established opposing effects of metabolically FA and UFA for coronary artery disease, stroke, hypertension and type 2 diabetes ${ }^{22}$, our results confirmed similarly strong metabolic components to peripheral artery disease and chronic kidney disease. These results are consistent with the well-established adverse metabolic effects of higher BMI on these diseases (contributing to atherosclerotic effects or linked to specific haemodynamic impacts) ${ }^{35}$. For two further cardiovascular conditions, heart failure and atrial fibrillation, the results were less certain. For these two conditions, the evidence of a predominantly metabolic effect of higher BMI was very clear - with the MR of UFA consistent with effects at least as strong as those for coronary artery disease. However, in contrast to the results for coronary artery disease, the MR of FA was consistent with no effect. This comparison between the effects of FA and UFA may indicate that there is a partial mechanical, or other non-metabolic component, as well as metabolic effect, perhaps mediated by excess weight of any type placing extra strain on the heart.

In contrast to the results for most of the cardio-metabolic diseases, our MR analyses provided evidence for a likely non-metabolic component mediating the effect of higher BMI on venous thromboembolism and deep vein thrombosis (two closely related conditions). This finding is clinically important as it suggests that treating metabolic risk factors associated with obesity without changing weight may not reduce the risk of deep vein thrombosis in individuals with obesity. Possible mechanisms could include higher intra-abdominal pressure (due to excess fat) and slower blood circulation in the lower limbs (due to a more sedentary lifestyle secondary to obesity, or mechanical occlusion of veins) promoting clot initiation and formation ${ }^{36}$.

Musculoskeletal diseases. We observed clear differences for the role of higher BMI in different musculoskeletal diseases. For gout, opposing effects of FA and UFA clearly indicated a metabolic effect. Gout is a form of inflammatory arthritis caused by the deposition of urate crystals within the joints ${ }^{37}$. Weight loss from bariatric surgery is associated with lower serum uric acid and lower risk of gout ${ }^{38}$. A previous MR study showed overall obesity, but not the central location of fat, increased the risk of gout ${ }^{39}$. The protective effect of FA could be due to improved insulin sensitivity leading to less insulin-enhanced reabsorption of organic anions such as urate ${ }^{40}$. In contrast to gout, our MR analysis provided evidence that a non-metabolic effect of higher adiposity is a likely cause of osteoarthritis and rheumatoid arthritis - with both FA and UFA leading to disease. For osteoarthritis, the effect of UFA was stronger than that of FA indicating both a metabolic and non-metabolic component. This is consistent with a causal association between higher adiposity and higher risk of osteoarthritis in non-weight bearing joints including hands ${ }^{41}$. For rheumatoid arthritis, the effects of FA and UFA were similar, suggesting the non-metabolic effect accentuating, or more readily unmasking, the autoimmune background risk, as the key BMI-related factor, although the confidence intervals were wider than those for osteoarthritis. For osteoporosis, we did not replicate the previous finding of a causal association between higher BMI and risk of osteoporosis (estimated by bone mineral density ${ }^{42}$ ); however, we observed a causal association between higher body fat percentage and a higher risk of osteoporosis with consistent risk increasing effects of both FA and UFA. This finding adds to the complex relationship between higher BMI and osteoporosis, where higher BMI at earlier ages may increase bone accrual, but in later years results in adverse effects.

Gastrointestinal diseases. We observed differences in the effects of BMI when comparing the two gastrointestinal diseases, although the results are less conclusive than those for the musculoskeletal conditions. Here, our results were consistent with a predominantly non-metabolic effect contributing to the association between higher BMI and higher risk of gallstones. Higher BMI has been shown to be causally associated with higher risk of gallstones ${ }^{43}$. There are several possible mechanisms that could explain how higher BMI without its adverse metabolic effects could increase the risk of gallstones. These could include a sedentary lifestyle and gallbladder hypomotility secondary to increased abdominal fat mass ${ }^{44}$. Metabolic mechanisms could include hepatic de novo cholesterol synthesis ${ }^{45,46}$. For gastro-oesophageal reflux, the consistent direction and effect sizes of higher FA and UFA indicates a non-metabolic component, an effect that may be mechanical and better explained by higher central adiposity rather than overall BMI ${ }^{15}$.

\section{Other diseases}

For most of the other diseases tested it was difficult to draw firm conclusions about the role of metabolically FA and UFA. For some diseases, this was in part to the lack of MR evidence for a role of any form of higher BMI. For example, our MR analyses provided no evidence for the role of higher BMI in the neurodegenerative diseases Alzheimer's disease, multiple sclerosis and Parkinson's. These results are consistent with some but not all previous studies. For 
example, higher BMI is listed as a key risk factor for Alzheimer's disease ${ }^{47}$, although with little evidence of causality, including MR studies that failed to show an effect ${ }^{48,49}$. In contrast to our results, recent MR studies have indicated that higher BMI is protective of Parkinson's disease ${ }^{12}$ and causally associated with higher risk of multiple sclerosis ${ }^{50}$. For the inflammatory skin disorder psoriasis, our results indicated that both higher BMI and higher body fat percentage are causally associated with higher risk but determining the underlying mechanism from the MR of FA and UFA was difficult. Higher BMI is a known cause of psoriasis ${ }^{6,51}$ and weight loss is a recommended treatment ${ }^{51}$. It is possible that both metabolic and non-metabolic pathways are driving the risk. The nonmetabolic pathways could include inflammation which is one of the possible causal mechanisms ${ }^{52,53}$. Further work is required to understand if psoriasis could be effectively treated by targeting the metabolic factors alone, or whether only weight loss will benefit such patients. For cancers, our results do not provide any clear additional insight into the likely mechanisms, with potentially stronger effects for BMI and UFA compared to body fat percentage in some analyses hard to explain biologically. The reasons why higher BMI is associated with cancers is uncertain, although several MR studies indicate that the association with many is causal ${ }^{54,55}$, and that central adiposity may play a role ${ }^{56}$. Exposure to higher insulin levels are a plausible mechanism and some studies have used MR to test insulin directly ${ }^{57-61}$. Our MR analysis reproduced the previous finding between higher adiposity and higher risk of endometrial ${ }^{62}$ and renal cancer carcinoma ${ }^{61}$, and lower risk of breast cancer ${ }^{11,58}$. In contrast to previous MR studies showing a causal link between higher BMI and higher risk of prostate cancer ${ }^{63,64}$, we identified a causal association between higher body fat percentage but lower risk of prostate cancer. The relationship between higher BMI and risk of breast cancer is complicated, with MR studies indicating that higher BMI is protective of post-menopausal breast cancer ${ }^{65}$. This contrasts with the epidemiological associations but could be explained by effects of childhood BMI66.

Our study had a number of limitations. First, we do not know all of the potential effects of the FA and UFA genetic variants on intermediary mechanisms. For example, the inflammatory profile of the FA variants needs further characterisation. However, the consistent association of the FA genetic variants with lower risk of a wide range of metabolic conditions - from type 2 diabetes where insulin resistance predominates, to stroke where atherosclerotic and blood pressure mechanisms predominate - indicates that these variants collectively represent a profile of higher adiposity and favourable metabolic factors. Second, for some diseases, we may have not had sufficient power to detect an effect of BMI or to separate the effects, and this could explain some of the null findings, especially for conditions where we might have expected an effect, such as pulmonary embolism and aortic aneurysm, but there were smaller numbers of cases available. Third, in some situations it was harder to interpret the results from the MR FA and UFA analyses, especially when one appeared to show an effect and the other did not. One possibility is that some diseases are a combination of both non-metabolic and metabolic effects. Osteoarthritis was the best example of this potential scenario because both FA and UFA increased the risk of disease, but UFA to a greater extent. However, for other diseases, it could be hard to detect a combined effect because the MR with FA could be protective (if metabolic effects pre-dominate), increase risk (if non-metabolic effects predominate) or null (if the two have similar effects). Finally, we used a false discovery rate (FDR) of 0.1 as a guide to discussing meaningful results. We observed 21 out of the 37 outcome diseases reaching an FDR of 0.1 (based on the Benjamini-Hochberg procedure) for BMI, and 19, 11 and 20 out of the 21 diseases causally associated with BMI reaching this FDR for body fat percentage, FA and UFA, respectively. Equivalent numbers for an FDR of 0.05 were 21 , 17, 11 and 17. Excluding the five metabolic conditions used in our previous study (which were all causally associated with BMI), these results are 16, 14, 7 and 15 for an FDR of 0.1 , and $16,12,7$ and 12 for an FDR of 0.05 . In addition to correcting for multiple tests, we noted that 74 of the $37 \times 4$ MR tests reached a pvalue of $<0.05$ when we would only expect 8 by chance, suggesting many of the tests that did not reach a strict Bonferroni $p<0.05$ were meaningful.

In summary, we provided genetic evidence that the adverse metabolic consequences of higher BMI lead to peripheral artery disease, heart failure, atrial fibrillation, chronic kidney disease, colorectal and ovarian cancer, and gout, and the adverse non-metabolic consequences of higher BMI likely contribute to osteoarthritis, rheumatoid arthritis, gastro-oesophageal reflux disease, cholelithiasis, depression, psoriasis and venous thromboembolism. These results emphasize that many people in the community who are of higher BMI are at risk of multiple chronic conditions that can severely impair their quality of life or cause morbidity or mortality, even if their metabolic parameters appear relatively normal.

\section{Declarations}

\section{Funding:}

H.Y. is funded by Diabetes UK RD Lawrence fellowship (grant: 17/0005594). S.M. and T.M.F. are funded by the MRC (MR/T002239/1). C.J.B. is supported by the World Cancer Research Fund (WCRF UK), as part of the World Cancer Research Fund International grant programme (IIG_2019_2009). J.A.B. works in a unit funded by the UK MRC (MC_UU_00011/1) and the University of Bristol. E.E.V. is supported by Diabetes UK (17/0005587) and the World Cancer Research Fund (WCRF UK), as part of the World Cancer Research Fund International grant programme (IIG_2019_2009) and works within the CRUK Integrative Cancer Epidemiology Programme (C18281/A29019).

Genetics and Epidemiology of Colorectal Cancer Consortium (GECCO): National Cancer Institute, National Institutes of Health, U.S. Department of Health and Human Services (U01 CA164930, U01 CA137088, R01 CA059045, R21 CA191312, R01201407). Genotyping/Sequencing services were provided by the Center for Inherited Disease Research (CIDR) contract number HHSN268201700006I and HHSN268201200008I. This research was funded in part through the $\mathrm{NIH} / \mathrm{NCl}$ Cancer Center Support Grant P30 CA015704. Scientific Computing Infrastructure at Fred Hutch funded by ORIP grant S100D028685

ASTERISK: a Hospital Clinical Research Program (PHRC-BRD09/C) from the University Hospital Center of Nantes (CHU de Nantes) and supported by the Regional Council of Pays de la Loire, the Groupement des Entreprises Françaises dans la Lutte contre le Cancer (GEFLUC), the Association Anne de Bretagne 
Génétique and the Ligue Régionale Contre le Cancer (LRCC).

The ATBC Study is supported by the Intramural Research Program of the U.S. National Cancer Institute, National Institutes of Health.

CLUE II funding was from the National Cancer Institute (U01 CA86308, Early Detection Research Network; P30 CA006973), National Institute on Aging (U01 AG18033), and the American Institute for Cancer Research. The content of this publication does not necessarily reflect the views or policies of the Department of Health and Human Services, nor does mention of trade names, commercial products, or organizations imply endorsement by the US government.

Maryland Cancer Registry (MCR)

Cancer data was provided by the Maryland Cancer Registry, Center for Cancer Prevention and Control, Maryland Department of Health, with funding from the State of Maryland and the Maryland Cigarette Restitution Fund. The collection and availability of cancer registry data is also supported by the Cooperative Agreement NU58DP006333, funded by the Centers for Disease Control and Prevention. Its contents are solely the responsibility of the authors and do not necessarily represent the official views of the Centers for Disease Control and Prevention or the Department of Health and Human Services.

ColoCare: This work was supported by the National Institutes of Health (grant numbers R01 CA189184 (Li/Ulrich), U01 CA206110 (Ulrich/Li/Siegel/Figueireido/Colditz, 2P30CA015704- 40 (Gilliland), R01 CA207371 (Ulrich/Li)), the Matthias Lackas-Foundation, the German Consortium for Translational Cancer Research, and the EU TRANSCAN initiative.

The Colon Cancer Family Registry (CCFR, www.coloncfr.org) is supported in part by funding from the National Cancer Institute (NCI), National Institutes of Health (NIH) (award U01 CA167551). Support for case ascertainment was provided in part from the Surveillance, Epidemiology, and End Results (SEER) Program and the following U.S. state cancer registries: AZ, CO, MN, NC, NH; and by the Victoria Cancer Registry (Australia) and Ontario Cancer Registry (Canada). The CCFR Set-1 (Illumina 1M/1M-Duo) and Set-2 (Illumina Omni1-Quad) scans were supported by NIH awards U01 CA122839 and R01 CA143247 (to GC). The CCFR Set-3 (Affymetrix Axiom CORECT Set array) was supported by NIH award U19 CA148107 and R01 CA81488 (to SBG). The CCFR Set-4 (Illumina OncoArray 600K SNP array) was supported by NIH award U19 CA148107 (to SBG) and by the Center for Inherited Disease Research (CIDR), which is funded by the NIH to the Johns Hopkins University, contract number HHSN268201200008I. Additional funding for the OFCCR/ARCTIC was through award GL201-043 from the Ontario Research Fund (to BWZ), award 112746 from the Canadian Institutes of Health Research (to TJH), through a Cancer Risk Evaluation (CaRE) Program grant from the Canadian Cancer Society (to SG), and through generous support from the Ontario Ministry of Research and Innovation. The SFCCR Illumina HumanCytoSNP array was supported in part through NCI/NIH awards U01 CA074794 (to JDP) and /U24 CA074794 and R01 CA076366 (to PAN). The content of this manuscript does not necessarily reflect the views or policies of the $\mathrm{NCl}$, NIH or any of the collaborating centers in the Colon Cancer Family Registry (CCFR), nor does mention of trade names, commercial products, or organizations imply endorsement by the US Government, any cancer registry, or the CCFR.

COLON: The COLON study is sponsored by Wereld Kanker Onderzoek Fonds, including funds from grant 2014/1179 as part of the World Cancer Research Fund International Regular Grant Programme, by Alpe d'Huzes and the Dutch Cancer Society (UM 2012-5653, UW 2013-5927, UW2015-7946), and by TRANSCAN (JTC2012-MetaboCCC, JTC2013-FOCUS). The Nqplus study is sponsored by a ZonMW investment grant (98-10030); by PREVIEW, the project PREVention of diabetes through lifestyle intervention and population studies in Europe and around the World (PREVIEW) project which received funding from the European Union Seventh Framework Programme (FP7/2007-2013) under grant no. 312057; by funds from TI Food and Nutrition (cardiovascular health theme), a public-private partnership on precompetitive research in food and nutrition; and by FOODBALL, the Food Biomarker Alliance, a project from JPI Healthy Diet for a Healthy Life.

Colorectal Cancer Transdisciplinary (CORECT) Study: The CORECT Study was supported by the National Cancer Institute, National Institutes of Health (NCI/NIH), U.S. Department of Health and Human Services (grant numbers U19 CA148107, R01 CA81488, P30 CA014089, R01 CA197350; P01 CA196569; R01 CA201407) and National Institutes of Environmental Health Sciences, National Institutes of Health (grant number T32 ES013678).

CORSA: "Österreichische Nationalbank Jubiläumsfondsprojekt” (12511) and Austrian Research Funding Agency (FFG) grant 829675.

CPS-II: The American Cancer Society funds the creation, maintenance, and updating of the Cancer Prevention Study-II (CPS-II) cohort. This study was conducted with Institutional Review Board approval.

CRCGEN: Colorectal Cancer Genetics \& Genomics, Spanish study was supported by Instituto de Salud Carlos III, co-funded by FEDER funds - a way to build Europe- (grants PI14-613 and PI09-1286), Agency for Management of University and Research Grants (AGAUR) of the Catalan Government (grant 2017SGR723), and Junta de Castilla y León (grant LE22A10-2). Sample collection of this work was supported by the Xarxa de Bancs de Tumors de Catalunya sponsored by Pla Director d'Oncología de Catalunya (XBTC), Plataforma Biobancos PT13/0010/0013 and ICOBIOBANC, sponsored by the Catalan Institute of Oncology.

Czech Republic CCS: This work was supported by the Czech Science Foundation (20-03997S) and by the Grant Agency of the Ministry of Health of the Czech Republic (grants NV18/03/00199 and NU21-07-00247).

DACHS: This work was supported by the German Research Council (BR 1704/6-1, BR 1704/6-3, BR 1704/6-4, CH 117/1-1, HO 5117/2-1, HE 5998/2-1, KL 2354/3-1, RO 2270/8-1 and BR 1704/17-1), the Interdisciplinary Research Program of the National Center for Tumor Diseases (NCT), Germany, and the German Federal Ministry of Education and Research (01KH0404, 01ER0814, 01ER0815, 01ER1505A and 01ER1505B).

DALS: National Institutes of Health (R01 CA48998 to M. L. Slattery).

Page $10 / 19$ 
EDRN: This work is funded and supported by the NCl, EDRN Grant (U01 CA 84968-06).

EPIC: The coordination of EPIC is financially supported by the European Commission (DGSANCO) and the International Agency for Research on Cancer. The national cohorts are supported by Danish Cancer Society (Denmark); Ligue Contre le Cancer, Institut Gustave Roussy, Mutuelle Générale de l'Education Nationale, Institut National de la Santé et de la Recherche Médicale (INSERM) (France); German Cancer Aid, German Cancer Research Center (DKFZ), Federal Ministry of Education and Research (BMBF), Deutsche Krebshilfe, Deutsches Krebsforschungszentrum and Federal Ministry of Education and Research (Germany); the Hellenic Health Foundation (Greece); Associazione Italiana per la Ricerca sul Cancro-AIRCItaly and National Research Council (Italy); Dutch Ministry of Public Health, Welfare and Sports (VWS), Netherlands Cancer Registry (NKR), LK Research Funds, Dutch Prevention Funds, Dutch ZON (Zorg Onderzoek Nederland), World Cancer Research Fund (WCRF), Statistics Netherlands (The Netherlands); ERC-2009-AdG 232997 and Nordforsk, Nordic Centre of Excellence programme on Food, Nutrition and Health (Norway); Health Research Fund (FIS), PI13/00061 to Granada, PI13/01162 to EPIC-Murcia, Regional Governments of Andalucía, Asturias, Basque Country, Murcia and Navarra, ISCIII RETIC (RD06/0020) (Spain); Swedish Cancer Society, Swedish Research Council and County Councils of Skåne and Västerbotten (Sweden); Cancer Research UK (14136 to EPIC-Norfolk; C570/A16491 and C8221/A19170 to EPICOxford), Medical Research Council (1000143 to EPIC-Norfolk, MR/M012190/1 to EPICOxford) (United Kingdom).

The EPIC-Norfolk study (https://doi.org/10.22025/2019.10.105.00004) has received funding from the Medical Research Council (MR/N003284/1 and MCUU_12015/1) and Cancer Research UK (C864/A14136). The genetics work in the EPIC-Norfolk study was funded by the Medical Research Council (MC_PC_13048). Metabolite measurements in the EPIC-Norfolk study were supported by the MRC Cambridge Initiative in Metabolic Science (MR/L00002/1) and the Innovative Medicines Initiative Joint Undertaking under EMIF grant agreement no. 115372.

EPICOLON: This work was supported by grants from Fondo de Investigación Sanitaria/FEDER (PI08/0024, PI08/1276, PS09/02368, PI11/00219, PI11/00681, PI14/00173, PI14/00230, PI17/00509, 17/00878, PI20/00113, PI20/00226, Acción Transversal de Cáncer), Xunta de Galicia (PGIDIT07PXIB9101209PR), Ministerio de Economia y Competitividad (SAF07-64873, SAF 2010-19273, SAF2014-54453R), Fundación Científica de la Asociación Española contra el Cáncer (GCB13131592CAST), Beca Grupo de Trabajo “Oncología” AEG (Asociación Española de Gastroenterología), Fundación Privada Olga Torres, FP7 CHIBCHA Consortium, Agència de Gestió d'Ajuts Universitaris i de Recerca (AGAUR, Generalitat de Catalunya, 2014SGR135, 2014SGR255, 2017SGR21, 2017SGR653), Catalan Tumour Bank Network (Pla Director d'Oncologia, Generalitat de Catalunya), PERIS (SLT002/16/00398, Generalitat de Catalunya), CERCA Programme (Generalitat de Catalunya) and COST Actions BM1206 and CA17118. CIBERehd is funded by the Instituto de Salud Carlos III.

ESTHER/VERDI. This work was supported by grants from the Baden-Württemberg Ministry of Science, Research and Arts and the German Cancer Aid.

Harvard cohorts (HPFS, NHS, PHS): HPFS is supported by the National Institutes of Health (P01 CA055075, UM1 CA167552, U01 CA167552, R01 CA137178, R01 CA151993, R35 CA197735, K07 CA190673, and P50 CA127003), NHS by the National Institutes of Health (R01 CA137178, P01 CA087969, UM1 CA186107, R01 CA151993, R35 CA197735, K07CA190673, and P50 CA127003) and PHS by the National Institutes of Health (R01 CA042182).

Hawaii Adenoma Study: NCl grants R01 CA72520.

HCES-CRC: the Hwasun Cancer Epidemiology Study-Colon and Rectum Cancer (HCES-CRC; grants from Chonnam National University Hwasun Hospital, HCRI15011-1).

Kentucky: This work was supported by the following grant support: Clinical Investigator Award from Damon Runyon Cancer Research Foundation (Cl-8); NCI R01CA136726.

LCCS: The Leeds Colorectal Cancer Study was funded by the Food Standards Agency and Cancer Research UK Programme Award (C588/A19167).

Melbourne Collaborative Cohort Study (MCCS) cohort recruitment was funded by VicHealth and Cancer Council Victoria. The MCCS was further augmented by Australian National Health and Medical Research Council grants 209057, 396414 and 1074383 and by infrastructure provided by Cancer Council Victoria. Cases and their vital status were ascertained through the Victorian Cancer Registry and the Australian Institute of Health and Welfare, including the National Death Index and the Australian Cancer Database.

Multiethnic Cohort (MEC) Study: National Institutes of Health (R37 CA54281, P01 CA033619, R01 CA063464 and U01 CA164973).

MECC: This work was supported by the National Institutes of Health, U.S. Department of Health and Human Services (R01 CA81488 to SBG and GR).

MSKCC: The work at Sloan Kettering in New York was supported by the Robert and Kate Niehaus Center for Inherited Cancer Genomics and the Romeo Milio Foundation. Moffitt: This work was supported by funding from the National Institutes of Health (grant numbers R01 CA189184, P30 CA076292), Florida Department of Health Bankhead-Coley Grant 09BN-13, and the University of South Florida Oehler Foundation. Moffitt contributions were supported in part by the Total Cancer Care Initiative, Collaborative Data Services Core, and Tissue Core at the H. Lee Moffitt Cancer Center \& Research Institute, a National Cancer Institute-designated Comprehensive Cancer Center (grant number P30 CA076292).

NCCCS I \& II: We acknowledge funding support for this project from the National Institutes of Health, R01 CA66635 and P30 DK034987.

NFCCR: This work was supported by an Interdisciplinary Health Research Team award from the Canadian Institutes of Health Research (CRT 43821); the National Institutes of Health, U.S. Department of Health and Human Serivces (U01 CA74783); and National Cancer Institute of Canada grants (18223 and 18226). The authors wish to acknowledge the contribution of Alexandre Belisle and the genotyping team of the McGill University and Génome Québec Innovation Centre, Montréal, Canada, for genotyping the Sequenom panel in the NFCCR samples. Funding was provided to Michael O. Woods by the Canadian Cancer Society Research Institute.

Page 11/19 
NSHDS: Swedish Research Council; Swedish Cancer Society; Cutting-Edge Research Grant and other grants from Region Västerbotten; Knut and Alice Wallenberg Foundation; Lion's Cancer Research Foundation at Umeå University; the Cancer Research Foundation in Northern Sweden; and the Faculty of Medicine, Umeå University, Umeå, Sweden.

OSUMC: OCCPI funding was provided by Pelotonia and HNPCC funding was provided by the NCI (CA16058 and CA67941).

PLCO: Intramural Research Program of the Division of Cancer Epidemiology and Genetics and supported by contracts from the Division of Cancer Prevention, National Cancer Institute, NIH, DHHS. Funding was provided by National Institutes of Health (NIH), Genes, Environment and Health Initiative (GEI) Z01 CP 010200, NIH U01 HG004446, and NIH GEI U01 HG 004438.

SEARCH: The University of Cambridge has received salary support in respect of PDPP from the NHS in the East of England through the Clinical Academic Reserve. Cancer Research UK (C490/A16561); the UK National Institute for Health Research Biomedical Research Centres at the University of Cambridge.

SELECT: Research reported in this publication was supported in part by the National Cancer Institute of the National Institutes of Health under Award Numbers U10 CA37429 (CD Blanke), and UM1 CA182883 (CM Tangen/IM Thompson). The content is solely the responsibility of the authors and does not necessarily represent the official views of the National Institutes of Health.

SMS and REACH: This work was supported by the National Cancer Institute (grant P01 CA074184 to J.D.P. and P.A.N., grants R01 CA097325, R03 CA153323, and K05 CA152715 to P.A.N., and the National Center for Advancing Translational Sciences at the National Institutes of Health (grant KL2 TR000421 to A.N.B.H.)

The Swedish Low-risk Colorectal Cancer Study: The study was supported by grants from the Swedish research council; K2015-55X-22674-01-4, K2008-55X20157-03-3, K2006-72X-20157-01-2 and the Stockholm County Council (ALF project).

Swedish Mammography Cohort and Cohort of Swedish Men: This work is supported by the Swedish Research Council /Infrastructure grant, the Swedish Cancer Foundation, and the Karolinska Institute's Distinguished Professor Award to Alicja Wolk.

UK Biobank: This research has been conducted using the UK Biobank Resource under Application Number 8614

VITAL: National Institutes of Health (K05 CA154337).

WHI: The WHI program is funded by the National Heart, Lung, and Blood Institute, National Institutes of Health, U.S. Department of Health and Human Services through contracts HHSN268201100046C, HHSN268201100001C, HHSN268201100002C, HHSN268201100003C, HHSN268201100004C, and HHSN271201100004C.

\section{Acknowledgements:}

This research has been conducted using the UK Biobank Resource under Application Number '9072' \& ' 9055 '. The authors would like to acknowledge the use of the University of Exeter High-Performance Computing (HPC) facility in carrying out this work. We acknowledge use of high-performance computing funded by an MRC Clinical Research Infrastructure award (MRC Grant: MR/M008924/1).

ASTERISK: We are very grateful to Dr. Bruno Buecher without whom this project would not have existed. We also thank all those who agreed to participate in this study, including the patients and the healthy control persons, as well as all the physicians, technicians and students.

CCFR: The Colon CFR graciously thanks the generous contributions of their study participants, dedication of study staff, and the financial support from the U.S. National Cancer Institute, without which this important registry would not exist. The authors would like to thank the study participants and staff of the Seattle Colon Cancer Family Registry and the Hormones and Colon Cancer study (CORE Studies).

CLUE II: We thank the participants of Clue II and appreciate the continued efforts of the staff at the Johns Hopkins George W. Comstock Center for Public Health Research and Prevention in the conduct of the Clue II Cohort Study.

COLON and NQplus: the authors would like to thank the COLON and NQplus investigators at Wageningen University \& Research and the involved clinicians in the participating hospitals.

CORSA: We kindly thank all those who contributed to the screening project Burgenland against CRC. Furthermore, we are grateful to Doris Mejri and Monika Hunjadi for laboratory assistance.

CPS-II: The authors thank the CPS-II participants and Study Management Group for their invaluable contributions to this research. The authors would also like to acknowledge the contribution to this study from central cancer registries supported through the Centers for Disease Control and Prevention National Program of Cancer Registries, and cancer registries supported by the National Cancer Institute Surveillance Epidemiology and End Results program. 
Czech Republic CCS: We are thankful to all clinicians in major hospitals in the Czech Republic, without whom the study would not be practicable. We are also sincerely grateful to all patients participating in this study.

DACHS: We thank all participants and cooperating clinicians, and Ute Handte-Daub, Utz Benscheid, Muhabbet Celik and Ursula Eilber for excellent technical assistance.

EDRN: We acknowledge all the following contributors to the development of the resource: University of Pittsburgh School of Medicine, Department of Gastroenterology, Hepatology and Nutrition: Lynda Dzubinski; University of Pittsburgh School of Medicine, Department of Pathology: Michelle Bisceglia; and University of Pittsburgh School of Medicine, Department of Biomedical Informatics.

EPIC: Where authors are identified as personnel of the International Agency for Research on Cancer/World Health Organization, the authors alone are responsible for the views expressed in this article and they do not necessarily represent the decisions, policy or views of the International Agency for Research on Cancer/World Health Organization.

The EPIC-Norfolk study: we are grateful to all the participants who have been part of the project and to the many members of the study teams at the University of Cambridge who have enabled this research.

EPICOLON: We are sincerely grateful to all patients participating in this study who were recruited as part of the EPICOLON project. We acknowledge the Spanish National DNA Bank, Biobank of Hospital Clínic-IDIBAPS and Biobanco Vasco for the availability of the samples. The work was carried out (in part) at the Esther Koplowitz Centre, Barcelona.

Harvard cohorts (HPFS, NHS, PHS): The study protocol was approved by the institutional review boards of the Brigham and Women's Hospital and Harvard T.H. Chan School of Public Health, and those of participating registries as required. We acknowledge Channing Division of Network Medicine, Department of Medicine, Brigham and Women's Hospital as home of the NHS. We would like to thank the participants and staff of the HPFS, NHS and PHS for their valuable contributions as well as the following state cancer registries for their help: $A L, A Z, A R, C A, C O, C T, D E, F L, G A, I D, I L, I N, I A, K Y, L A, M E, M D, M A, M I, N E, N H, N J$, NY, NC, ND, OH, OK, OR, PA, RI, SC, TN, TX, VA, WA, WY. The authors assume full responsibility for analyses and interpretation of these data.

Interval: A complete list of the investigators and contributors to the INTERVAL trial is provided in reference (32). The academic coordinating centre would like to thank blood donor centre staff and blood donors for participating in the INTERVAL trial.

Kentucky: We would like to acknowledge the staff at the Kentucky Cancer Registry.

LCCS: We acknowledge the contributions of Jennifer Barrett, Robin Waxman, Gillian Smith and Emma Northwood in conducting this study.

NCCCS I \& II: We would like to thank the study participants, and the NC Colorectal Cancer Study staff.

NSHDS investigators thank the Biobank Research Unit at Umeå University, the Västerbotten Intervention Programme, the Northern Sweden MONICA study and Region Västerbotten for providing data and samples and acknowledge the contribution from Biobank Sweden, supported by the Swedish Research Council (VR 2017-00650).

PLCO: The authors thank the PLCO Cancer Screening Trial screening center investigators and the staff from Information Management Services Inc and Westat Inc. Most importantly, we thank the study participants for their contributions that made this study possible.

SEARCH: We thank the SEARCH team.

SELECT: We thank the research and clinical staff at the sites that participated on SELECT study, without whom the trial would not have been successful. We are also grateful to the 35,533 dedicated men who participated in SELECT.

UK Biobank: We would like to thank the participants and researchers UK Biobank for their participation and acquisition of data.

WHI: The authors thank the WHI investigators and staff for their dedication, and the study participants for making the program possible. A full listing of WHI investigators can be found at: http://www.whi.org/researchers/Documents\%20\%20Write\%20a\%20Paper/WHI\%20Investigator\%20Short\%20List.pdf

\section{Competing interests:}

The authors have declared that no competing interests exist except for Tim Frayling who has consulted for Boehringer Ingelheim and Sanofi and has a student supported by GSK.

\section{Disclaimer:}

Where authors are identified as personnel of the International Agency for Research on Cancer / World Health Organization, the authors alone are responsible for the views expressed in this article and they do not necessarily represent the decisions, policy or views of the International Agency for Research on Cancer / 


\section{References}

1 Smith, G. D. \& Ebrahim, S. Mendelian randomization: prospects, potentials, and limitations. Int J Epidemio/ 33, 30-42, doi:10.1093/ije/dyh132 (2004).

2 Tachmazidou, I. et al. Identification of new therapeutic targets for osteoarthritis through genome-wide analyses of UK Biobank data. Nat Genet 51, 230236, doi:10.1038/s41588-018-0327-1 (2019).

3 Thrift, A. P. et al. Mendelian Randomization Study of Body Mass Index and Colorectal Cancer Risk. Cancer Epidemiol Biomarkers Prev 24, 1024-1031, doi:10.1158/1055-9965.Epi-14-1309 (2015).

4 Suzuki, S. et al. Body mass index and colorectal cancer risk: A Mendelian randomization study. Cancer Sci 112, 1579-1588, doi:10.1111/cas.14824 (2021).

5 Bull, C. J. et al. Adiposity, metabolites, and colorectal cancer risk: Mendelian randomization study. BMC Med 18, 396, doi:10.1186/s12916-020-01855-9 (2020).

6 Budu-Aggrey, A. et al. Evidence of a causal relationship between body mass index and psoriasis: A mendelian randomization study. PLoS Med 16, e1002739, doi:10.1371/journal.pmed.1002739 (2019).

7 Hägg, S. et al. Adiposity as a cause of cardiovascular disease: a Mendelian randomization study. Int J Epidemio/ 44, 578-586, doi:10.1093/ije/dyv094 (2015).

8 Cheng, L. et al. Exposing the Causal Effect of Body Mass Index on the Risk of Type 2 Diabetes Mellitus: A Mendelian Randomization Study. Front Genet 10, 94, doi:10.3389/fgene.2019.00094 (2019).

9 Corbin, L. J. et al. BMI as a Modifiable Risk Factor for Type 2 Diabetes: Refining and Understanding Causal Estimates Using Mendelian Randomization. Diabetes 65, 3002-3007, doi:10.2337/db16-0418 (2016).

10 Fall, T. et al. The role of adiposity in cardiometabolic traits: a Mendelian randomization analysis. PLoS Med 10, e1001474, doi:10.1371/journal.pmed.1001474 (2013).

11 Guo, Y. et al. Genetically Predicted Body Mass Index and Breast Cancer Risk: Mendelian Randomization Analyses of Data from 145,000 Women of European Descent. PLoS Med 13, e1002105, doi:10.1371/journal.pmed.1002105 (2016).

12 Noyce, A. J. et al. Estimating the causal influence of body mass index on risk of Parkinson disease: A Mendelian randomisation study. PLoS Med 14, e1002314, doi:10.1371/journal.pmed.1002314 (2017).

13 Emdin, C. A., Khera, A. V. \& Kathiresan, S. Genetic Predisposition to Abdominal Obesity and Cardiometabolic Risk-Reply. Jama 317, 2334-2335, doi:10.1001/jama.2017.5044 (2017).

14 Cornish, A. J. et al. Modifiable pathways for colorectal cancer: a mendelian randomisation analysis. Lancet Gastroenterol Hepatol 5, 55-62, doi:10.1016/s2468-1253(19)30294-8 (2020).

15 Green, H. D. et al. Genetic evidence that higher central adiposity causes gastro-oesophageal reflux disease: a Mendelian randomization study. Int J Epidemio/ 49, 1270-1281, doi:10.1093/ije/dyaa082 (2020).

$16 \mathrm{Ji}$, Y. et al. Genome-Wide and Abdominal MRI Data Provide Evidence That a Genetically Determined Favorable Adiposity Phenotype Is Characterized by Lower Ectopic Liver Fat and Lower Risk of Type 2 Diabetes, Heart Disease, and Hypertension. Diabetes 68, 207-219, doi:10.2337/db18-0708 (2019).

17 Lotta, L. A. et al. Integrative genomic analysis implicates limited peripheral adipose storage capacity in the pathogenesis of human insulin resistance. Nat Genet 49, 17-26, doi:10.1038/ng.3714 (2017).

18 Kilpeläinen, T. O. et al. Genetic variation near IRS1 associates with reduced adiposity and an impaired metabolic profile. Nat Genet 43, 753-760, doi:10.1038/ng.866 (2011).

19 Huang, L. O. et al. Genome-wide discovery of genetic loci that uncouple excess adiposity from its comorbidities. Nat Metab 3, 228-243, doi:10.1038/s42255-021-00346-2 (2021).

20 Semple, R. K., Savage, D. B., Cochran, E. K., Gorden, P. \& O'Rahilly, S. Genetic syndromes of severe insulin resistance. Endocr Rev 32, 498-514, doi:10.1210/er.2010-0020 (2011).

21 Stears, A., O'Rahilly, S., Semple, R. K. \& Savage, D. B. Metabolic insights from extreme human insulin resistance phenotypes. Best Pract Res Clin Endocrinol Metab 26, 145-157, doi:10.1016/j.beem.2011.09.003 (2012). 
22 Martin, S. et al. Genetic evidence for different adiposity phenotypes and their opposing influence on ectopic fat and risk of cardiometabolic disease. Diabetes, doi:10.2337/db21-0129 (2021).

23 FinnGen. (2020).

24 Collins, R. What makes UK Biobank special? Lancet 379, 1173-1174, doi:10.1016/s0140-6736(12)60404-8 (2012).

25 Locke, A. E. et al. Genetic studies of body mass index yield new insights for obesity biology. Nature 518, 197-206, doi:10.1038/nature14177 (2015).

26 Loh, P. R. et al. Efficient Bayesian mixed-model analysis increases association power in large cohorts. Nat Genet 47, 284-290, doi:10.1038/ng.3190 (2015).

27 Pierce, B. L. \& Burgess, S. Efficient design for Mendelian randomization studies: subsample and 2-sample instrumental variable estimators. Am J Epidemiol 178, 1177-1184, doi:10.1093/aje/kwt084 (2013).

28 Viechtbauer, W. Conducting meta-analyses in R with the metafor package. Journal of Statistical Software 36, 1-48 (2010).

29 Yavorska, O. O. \& Burgess, S. MendelianRandomization: an R package for performing Mendelian randomization analyses using summarized data. Int J Epidemiol 46, 1734-1739, doi:10.1093/ije/dyx034 (2017).

30 R: A Language and Environment for Statistical Computing (R Foundation for Statistical Computing, Vienna, Austria, 2020).

31 Benjamini, Y. \& Hochberg, Y. Controlling the false discovery rate: a practical and powerful approach to multiple testing. Journal of the Royal statistical society: series B (Methodological) 57, 289-300 (1995).

32 Larsson, S. C., Bäck, M., Rees, J. M. B., Mason, A. M. \& Burgess, S. Body mass index and body composition in relation to 14 cardiovascular conditions in UK Biobank: a Mendelian randomization study. Eur Heart J 41, 221-226, doi:10.1093/eurheartj/ehz388 (2020).

33 Riaz, H. et al. Association Between Obesity and Cardiovascular Outcomes: A Systematic Review and Meta-analysis of Mendelian Randomization Studies. JAMA Netw Open 1, e183788, doi:10.1001/jamanetworkopen.2018.3788 (2018).

$34 \mathrm{Xu}, \mathrm{X}$. et al. Obesity as a cause of kidney disease - insights from Mendelian randomisation studies. medRxiv, 2020.2009.2013.20155234, doi:10.1101/2020.09.13.20155234 (2020).

35 Sattar, N. \& McGuire, D. K. Pathways to Cardiorenal Complications in Type 2 Diabetes Mellitus: A Need to Rethink. Circulation 138, 7-9, doi:10.1161/circulationaha.118.035083 (2018).

36 Lorenzet, R., Napoleone, E., Cutrone, A. \& Donati, M. B. Thrombosis and obesity: cellular bases. Thromb Res 129, 285-289, doi:10.1016/j.thromres.2011.10.021 (2012).

37 Dalbeth, N., Merriman, T. R. \& Stamp, L. K. Gout. Lancet 388, 2039-2052, doi:10.1016/s0140-6736(16)00346-9 (2016).

38 Maglio, C. et al. Effects of bariatric surgery on gout incidence in the Swedish Obese Subjects study: a non-randomised, prospective, controlled intervention trial. Ann Rheum Dis 76, 688-693, doi:10.1136/annrheumdis-2016-209958 (2017).

39 Larsson, S. C., Burgess, S. \& Michaëlsson, K. Genetic association between adiposity and gout: a Mendelian randomization study. Rheumatology (Oxford) 57, 2145-2148, doi:10.1093/rheumatology/key229 (2018).

40 Choi, H. K., Mount, D. B. \& Reginato, A. M. Pathogenesis of gout. Ann Intern Med 143, 499-516, doi:10.7326/0003-4819-143-7-200510040-00009 (2005).

41 Reyes, C. et al. Association Between Overweight and Obesity and Risk of Clinically Diagnosed Knee, Hip, and Hand Osteoarthritis: A Population-Based Cohort Study. Arthritis Rheumatol 68, 1869-1875, doi:10.1002/art.39707 (2016).

42 Song, J. et al. The Relationship Between Body Mass Index and Bone Mineral Density: A Mendelian Randomization Study. Calcif Tissue Int 107, 440445, doi:10.1007/s00223-020-00736-w (2020).

43 Yuan, S., Gill, D., Giovannucci, E. L. \& Larsson, S. C. Obesity, Type 2 Diabetes, Lifestyle Factors, and Risk of Gallstone Disease: A Mendelian Randomization Investigation. Clin Gastroenterol Hepatol, doi:10.1016/j.cgh.2020.12.034 (2021).

44 Mathus-Vliegen, E. M., Van lerland-Van Leeuwen, M. L. \& Terpstra, A. Determinants of gallbladder kinetics in obesity. Dig Dis Sci 49, 9-16, doi:10.1023/b:ddas.0000011595.39555.c0 (2004).

45 Ståhlberg, D. et al. Hepatic cholesterol metabolism in human obesity. Hepatology 25, 1447-1450, doi:10.1002/hep.510250623 (1997).

46 Cruz-Monserrate, Z., Conwell, D. L. \& Krishna, S. G. The Impact of Obesity on Gallstone Disease, Acute Pancreatitis, and Pancreatic Cancer. Gastroenterol Clin North Am 45, 625-637, doi:10.1016/j.gtc.2016.07.010 (2016). 
47 Livingston, G. et al. Dementia prevention, intervention, and care: 2020 report of the Lancet Commission. Lancet 396, 413-446, doi:10.1016/s01406736(20)30367-6 (2020).

48 Larsson, S. C. et al. Modifiable pathways in Alzheimer's disease: Mendelian randomisation analysis. Bmj 359, j5375, doi:10.1136/bmj.j5375 (2017).

49 Nordestgaard, L. T., Tybjærg-Hansen, A., Nordestgaard, B. G. \& Frikke-Schmidt, R. Body Mass Index and Risk of Alzheimer's Disease: A Mendelian Randomization Study of 399,536 Individuals. J Clin Endocrinol Metab 102, 2310-2320, doi:10.1210/jc.2017-00195 (2017).

50 Mokry, L. E. et al. Obesity and Multiple Sclerosis: A Mendelian Randomization Study. PLoS Med 13, e1002053, doi:10.1371/journal.pmed.1002053 (2016).

51 Iskandar, I. Y. et al. Demographics and disease characteristics of patients with psoriasis enrolled in the British Association of Dermatologists Biologic Interventions Register. Br J Dermatol 173, 510-518, doi:10.1111/bjd.13908 (2015).

52 Sbidian, E. et al. Systemic pharmacological treatments for chronic plaque psoriasis: a network meta-analysis. Cochrane Database Syst Rev 12, Cd011535, doi:10.1002/14651858.CD011535.pub2 (2017).

53 Dowlatshahi, E. A., van der Voort, E. A., Arends, L. R. \& Nijsten, T. Markers of systemic inflammation in psoriasis: a systematic review and meta-analysis. Br J Dermatol 169, 266-282, doi:10.1111/bjd.12355 (2013).

54 Mariosa, D., Carreras-Torres, R., Martin, R. M., Johansson, M. \& Brennan, P. Commentary: What can Mendelian randomization tell us about causes of cancer? Int J Epidemio/ 48, 816-821, doi:10.1093/ije/dyz151 (2019).

55 Vincent, E. E. \& Yaghootkar, H. Using genetics to decipher the link between type 2 diabetes and cancer: shared aetiology or downstream consequence? Diabetologia 63, 1706-1717, doi:10.1007/s00125-020-05228-y (2020).

56 Jarvis, D. et al. Mendelian randomisation analysis strongly implicates adiposity with risk of developing colorectal cancer. Br J Cancer $115,266-272$, doi:10.1038/bjc.2016.188 (2016).

57 Nead, K. T. et al. Evidence of a Causal Association Between Insulinemia and Endometrial Cancer: A Mendelian Randomization Analysis. J Natl Cancer Inst 107, doi:10.1093/jnci/djv178 (2015).

58 Shu, X. et al. Associations of obesity and circulating insulin and glucose with breast cancer risk: a Mendelian randomization analysis. Int $J$ Epidemiol 48, 795-806, doi:10.1093/ije/dyy201 (2019).

59 Carreras-Torres, R. et al. Obesity, metabolic factors and risk of different histological types of lung cancer: A Mendelian randomization study. PLoS One 12, e0177875, doi:10.1371/journal.pone.0177875 (2017).

60 Carreras-Torres, R. et al. The Role of Obesity, Type 2 Diabetes, and Metabolic Factors in Pancreatic Cancer: A Mendelian Randomization Study. J Natl Cancer Inst 109, doi:10.1093/jnci/djx012 (2017).

61 Johansson, M. et al. The influence of obesity-related factors in the etiology of renal cell carcinoma-A mendelian randomization study. PLoS Med 16, e1002724, doi:10.1371/journal.pmed.1002724 (2019).

62 Painter, J. N. et al. Genetic Risk Score Mendelian Randomization Shows that Obesity Measured as Body Mass Index, but not Waist:Hip Ratio, Is Causal for Endometrial Cancer. Cancer Epidemiol Biomarkers Prev 25, 1503-1510, doi:10.1158/1055-9965.Epi-16-0147 (2016).

63 Kazmi, N. et al. Appraising causal relationships of dietary, nutritional and physical-activity exposures with overall and aggressive prostate cancer: twosample Mendelian-randomization study based on 79148 prostate-cancer cases and 61106 controls. Int J Epidemio/ 49, 587-596, doi:10.1093/ije/dyz235 (2020).

64 Davies, N. M. et al. The effects of height and BMI on prostate cancer incidence and mortality: a Mendelian randomization study in 20,848 cases and 20,214 controls from the PRACTICAL consortium. Cancer Causes Control 26, 1603-1616, doi:10.1007/s10552-015-0654-9 (2015).

65 Gao, C. et al. Mendelian randomization study of adiposity-related traits and risk of breast, ovarian, prostate, lung and colorectal cancer. Int J Epidemiol 45, 896-908, doi:10.1093/ije/dyw129 (2016).

66 Richardson, T. G., Sanderson, E., Elsworth, B., Tilling, K. \& Davey Smith, G. Use of genetic variation to separate the effects of early and later life adiposity on disease risk: mendelian randomisation study. Bmj 369, m1203, doi:10.1136/bmj.m1203 (2020).

\section{Tables}

Table 1. The inverse-variance weighted two-sample MR analysis/meta-analysis of 37 identified diseases from published GWAS and/or FinnGen for body mass index (BMI), body fat percentage, "favourable adiposity" (FA) and "unfavourable adiposity" (UFA) clusters. OR: odds ratio, 95\% Cl: 95\% confidence interval; P: p-value. 


\begin{tabular}{|c|c|c|c|c|c|c|c|c|c|c|c|c|c|c|}
\hline \multirow[b]{2}{*}{ System } & \multirow[b]{2}{*}{ Disease } & \multirow[b]{2}{*}{ Study } & \multicolumn{3}{|l|}{ BMI } & \multicolumn{3}{|c|}{ Body fat percentage } & \multicolumn{3}{|l|}{ FA } & \multicolumn{3}{|l|}{ UFA } \\
\hline & & & OR & $\begin{array}{l}95 \% \\
\mathrm{Cl}\end{array}$ & $\mathbf{P}$ & OR & $\begin{array}{l}95 \% \\
\mathrm{Cl}\end{array}$ & $\mathbf{P}$ & OR & $\begin{array}{l}95 \% \\
\mathrm{Cl}\end{array}$ & $\mathbf{P}$ & OR & $\begin{array}{l}95 \% \\
\mathrm{Cl}\end{array}$ & $\mathbf{P}$ \\
\hline $\begin{array}{l}\text { Cardiovascular } \\
\text { and metabolic }\end{array}$ & $\begin{array}{l}\text { Abdominal } \\
\text { aneurysm }\end{array}$ & $\begin{array}{l}\text { Meta- } \\
\text { analysis }\end{array}$ & 1.16 & $\begin{array}{l}(0.83 \\
1.62)\end{array}$ & 0.394 & 1.16 & $\begin{array}{l}(0.91 \\
1.48)\end{array}$ & 0.233 & 0.81 & $\begin{array}{l}(0.43 \\
1.51)\end{array}$ & 0.506 & 1.26 & $\begin{array}{l}(0.71 \\
2.26)^{\prime}\end{array}$ & 0.430 \\
\hline $\begin{array}{l}\text { Cardiovascular } \\
\text { and metabolic }\end{array}$ & Atrial fibrillation & $\begin{array}{l}\text { Meta- } \\
\text { analysis }\end{array}$ & 1.65 & $\begin{array}{l}(1.33 \\
2.05)\end{array}$ & $\begin{array}{l}5 . \mathrm{E}- \\
06\end{array}$ & 1.53 & $\begin{array}{l}(1.21 \\
1.92)\end{array}$ & $\begin{array}{l}3 . \mathrm{E}- \\
04\end{array}$ & 0.79 & $\begin{array}{l}(0.39 \\
1.61)\end{array}$ & 0.518 & 1.78 & $\begin{array}{l}(1.50 \\
2.12)\end{array}$ & $\begin{array}{l}6 . \mathrm{E}- \\
11\end{array}$ \\
\hline $\begin{array}{l}\text { Cardiovascular } \\
\text { and metabolic }\end{array}$ & $\begin{array}{l}\text { Coronary artery } \\
\text { disease }\end{array}$ & $\begin{array}{l}\text { Meta- } \\
\text { analysis }\end{array}$ & 1.41 & $\begin{array}{l}(1.10 \\
1.81)\end{array}$ & 0.007 & 1.39 & $\begin{array}{l}(1.16, \\
1.68)\end{array}$ & $\begin{array}{l}5 . \mathrm{E}- \\
04\end{array}$ & 0.34 & $\begin{array}{l}(0.25 \\
0.47)\end{array}$ & $\begin{array}{l}2 . \mathrm{E}- \\
11\end{array}$ & 1.66 & $\begin{array}{l}(1.08 \\
2.54)\end{array}$ & 0.021 \\
\hline $\begin{array}{l}\text { Cardiovascular } \\
\text { and metabolic }\end{array}$ & $\begin{array}{l}\text { Deep vein } \\
\text { thrombosis }\end{array}$ & FinnGen & 1.68 & $\begin{array}{l}(1.20 \\
2.37)^{\prime}\end{array}$ & 0.004 & 1.71 & $\begin{array}{l}(1.40 \\
2.09)\end{array}$ & $\begin{array}{l}\text { 2.E- } \\
07\end{array}$ & 3.45 & $\begin{array}{l}(1.81 \\
6.57)^{\prime}\end{array}$ & $\begin{array}{l}6 . \mathrm{E}- \\
04\end{array}$ & 2.05 & $\begin{array}{l}(1.15 \\
3.64)\end{array}$ & 0.020 \\
\hline $\begin{array}{l}\text { Cardiovascular } \\
\text { and metabolic }\end{array}$ & Heart failure & $\begin{array}{l}\text { Meta- } \\
\text { analysis }\end{array}$ & 1.86 & $\begin{array}{l}(1.60 \\
2.16)\end{array}$ & $\begin{array}{l}2 . \mathrm{E}- \\
16\end{array}$ & 1.76 & $\begin{array}{l}(1.65, \\
1.88)\end{array}$ & $\begin{array}{l}\text { 2.E- } \\
67\end{array}$ & 0.85 & $\begin{array}{l}(0.65 \\
1.11)\end{array}$ & 0.238 & 2.29 & $\begin{array}{l}(1.85 \\
2.83)\end{array}$ & $\begin{array}{l}2 . \mathrm{E}- \\
14\end{array}$ \\
\hline $\begin{array}{l}\text { Cardiovascular } \\
\text { and metabolic }\end{array}$ & Hypertension & FinnGen & 2.18 & $\begin{array}{l}(1.80 \\
2.64)\end{array}$ & $\begin{array}{l}2 . \mathrm{E}- \\
11\end{array}$ & 2.01 & $\begin{array}{l}(1.79, \\
2.26)^{\prime}\end{array}$ & $\begin{array}{l}6 . \mathrm{E}- \\
29\end{array}$ & 0.34 & $\begin{array}{l}(0.21 \\
0.55)\end{array}$ & $\begin{array}{l}\text { 1.E- } \\
04\end{array}$ & 3.03 & $\begin{array}{l}(2.18 \\
4.22)\end{array}$ & $\begin{array}{l}\text { 2.E- } \\
07\end{array}$ \\
\hline $\begin{array}{l}\text { Cardiovascular } \\
\text { and metabolic }\end{array}$ & $\begin{array}{l}\text { Peripheral artery } \\
\text { disease }\end{array}$ & FinnGen & 1.87 & $\begin{array}{l}(1.46 \\
2.39)\end{array}$ & $\begin{array}{l}4 . \mathrm{E}- \\
06\end{array}$ & 1.80 & $\begin{array}{l}(1.52, \\
2.14)\end{array}$ & $\begin{array}{l}4 . \mathrm{E}- \\
11\end{array}$ & 0.20 & $\begin{array}{l}(0.11 \\
0.38)^{\prime}\end{array}$ & $\begin{array}{l}2 . \mathrm{E}- \\
05\end{array}$ & 3.31 & $\begin{array}{l}(2.09 \\
5.24)\end{array}$ & $\begin{array}{l}\text { 1.E- } \\
05\end{array}$ \\
\hline $\begin{array}{l}\text { Cardiovascular } \\
\text { and metabolic }\end{array}$ & $\begin{array}{l}\text { Pulmonary } \\
\text { embolism }\end{array}$ & FinnGen & 1.23 & $\begin{array}{l}(0.85 \\
1.78)\end{array}$ & 0.269 & 1.26 & $\begin{array}{l}(1.02, \\
1.55)\end{array}$ & 0.032 & 2.40 & $\begin{array}{l}(0.99 \\
5.84)^{\prime}\end{array}$ & 0.061 & 1.66 & $\begin{array}{l}(0.94 \\
2.94)\end{array}$ & 0.090 \\
\hline $\begin{array}{l}\text { Cardiovascular } \\
\text { and metabolic }\end{array}$ & Stroke & $\begin{array}{l}\text { Meta- } \\
\text { analysis }\end{array}$ & 1.19 & $\begin{array}{l}(1.07 \\
1.31)^{\prime}\end{array}$ & $\begin{array}{l}1 . \mathrm{E}- \\
03\end{array}$ & 1.23 & $\begin{array}{l}(1.15, \\
1.31)\end{array}$ & $\begin{array}{l}7 . \mathrm{E}- \\
10\end{array}$ & 0.65 & $\begin{array}{l}(0.52 \\
0.83)\end{array}$ & $\begin{array}{l}4 . \mathrm{E}- \\
04\end{array}$ & 1.43 & $\begin{array}{l}(1.23 \\
1.67)\end{array}$ & $\begin{array}{l}3 . \mathrm{E}- \\
06\end{array}$ \\
\hline $\begin{array}{l}\text { Cardiovascular } \\
\text { and metabolic }\end{array}$ & $\begin{array}{l}\text { Venous } \\
\text { thromboembolism }\end{array}$ & $\begin{array}{l}\text { Meta- } \\
\text { analysis }\end{array}$ & 1.45 & $\begin{array}{l}(1.27 \\
1.67)^{\prime}\end{array}$ & $\begin{array}{l}\text { 8.E- } \\
08\end{array}$ & 1.57 & $\begin{array}{l}(1.40 \\
1.77)\end{array}$ & $\begin{array}{l}4 . \mathrm{E}- \\
14\end{array}$ & 2.52 & $\begin{array}{l}(1.82, \\
3.47)\end{array}$ & $\begin{array}{l}2 . \mathrm{E}- \\
08\end{array}$ & 1.63 & $\begin{array}{l}(1.25 \\
2.13)\end{array}$ & $\begin{array}{l}3 . \mathrm{E}- \\
04\end{array}$ \\
\hline $\begin{array}{l}\text { Cardiovascular } \\
\text { and metabolic }\end{array}$ & $\begin{array}{l}\text { Polycystic ovary } \\
\text { syndrome }\end{array}$ & $\begin{array}{l}\text { Meta- } \\
\text { analysis }\end{array}$ & 4.11 & $\begin{array}{l}(2.97 \\
5.70)^{\prime}\end{array}$ & $\begin{array}{l}2 . \mathrm{E}- \\
17\end{array}$ & 2.64 & $\begin{array}{l}(2.11, \\
3.29)^{\prime}\end{array}$ & $\begin{array}{l}1 . \mathrm{E}- \\
17\end{array}$ & 0.51 & $\begin{array}{l}(0.21 \\
1.23)\end{array}$ & 0.132 & 7.13 & $\begin{array}{l}\text { (3.66, } \\
13.90)\end{array}$ & $\begin{array}{l}\text { 8.E- } \\
09\end{array}$ \\
\hline $\begin{array}{l}\text { Cardiovascular } \\
\text { and metabolic }\end{array}$ & Type 2 diabetes & $\begin{array}{l}\text { Meta- } \\
\text { analysis }\end{array}$ & 2.97 & $\begin{array}{l}(2.60 \\
3.39)\end{array}$ & $\begin{array}{l}\text { 3.E- } \\
57\end{array}$ & 2.38 & $\begin{array}{l}(2.12, \\
2.68)\end{array}$ & $\begin{array}{l}5 . \mathrm{E}- \\
49\end{array}$ & 0.11 & $\begin{array}{l}(0.08 \\
0.16)\end{array}$ & $\begin{array}{l}4 . \mathrm{E}- \\
33\end{array}$ & 5.50 & $\begin{array}{l}(4.29 \\
7.05)\end{array}$ & $\begin{array}{l}4 . \mathrm{E}- \\
41\end{array}$ \\
\hline $\begin{array}{l}\text { Cardiovascular } \\
\text { and metabolic }\end{array}$ & $\begin{array}{l}\text { Chronic kidney } \\
\text { disease }\end{array}$ & $\begin{array}{l}\text { Meta- } \\
\text { analysis }\end{array}$ & 1.21 & $\begin{array}{l}(1.08, \\
1.36)\end{array}$ & 0.002 & 1.25 & $\begin{array}{l}(0.98 \\
1.59)\end{array}$ & 0.071 & 0.64 & $\begin{array}{l}(0.48 \\
0.84)\end{array}$ & 0.002 & 1.19 & $\begin{array}{l}(0.97 \\
1.45)\end{array}$ & 0.092 \\
\hline Musculoskeletal & Gout & $\begin{array}{l}\text { Meta- } \\
\text { analysis }\end{array}$ & 1.68 & $\begin{array}{l}(1.42 \\
2.00)\end{array}$ & $\begin{array}{l}\text { 3.E- } \\
09\end{array}$ & 1.66 & $\begin{array}{l}(1.45, \\
1.89)\end{array}$ & $\begin{array}{l}3 . \mathrm{E}- \\
14\end{array}$ & 0.44 & $\begin{array}{l}(0.29 \\
0.68)\end{array}$ & $\begin{array}{l}2 . \mathrm{E}- \\
04\end{array}$ & 2.49 & $\begin{array}{l}(1.88 \\
3.29)\end{array}$ & $\begin{array}{l}2 . \mathrm{E}- \\
10\end{array}$ \\
\hline Musculoskeletal & Osteoarthritis & $\begin{array}{l}\text { Meta- } \\
\text { analysis }\end{array}$ & 1.72 & $\begin{array}{l}(1.37 \\
2.16)\end{array}$ & $\begin{array}{l}\text { 2.E- } \\
06\end{array}$ & 1.82 & $\begin{array}{l}(1.73, \\
1.91)\end{array}$ & $\begin{array}{l}1 . \mathrm{E}- \\
124\end{array}$ & 1.45 & $\begin{array}{l}(1.19 \\
1.76)\end{array}$ & $\begin{array}{l}2 . \mathrm{E}- \\
04\end{array}$ & 2.20 & $\begin{array}{l}(1.64 \\
2.95)\end{array}$ & $\begin{array}{l}1 . \mathrm{E}- \\
07\end{array}$ \\
\hline Musculoskeletal & Osteoporosis & $\begin{array}{l}\text { Meta- } \\
\text { analysis }\end{array}$ & 1.04 & $\begin{array}{l}(0.77 \\
1.40)\end{array}$ & 0.808 & 1.13 & $\begin{array}{l}(1.03, \\
1.25)\end{array}$ & 0.010 & 1.13 & $\begin{array}{l}(0.77 \\
1.64)^{\prime}\end{array}$ & 0.530 & 1.18 & $\begin{array}{l}(1.01, \\
1.37)\end{array}$ & 0.034 \\
\hline Musculoskeletal & $\begin{array}{l}\text { Rheumatoid } \\
\text { arthritis }\end{array}$ & $\begin{array}{l}\text { Meta- } \\
\text { analysis }\end{array}$ & 1.23 & $\begin{array}{l}(1.04 \\
1.46)\end{array}$ & 0.017 & 1.49 & $\begin{array}{l}(1.30 \\
1.70)\end{array}$ & $\begin{array}{l}\text { 5.E- } \\
09\end{array}$ & 1.95 & $\begin{array}{l}(1.24, \\
3.08)\end{array}$ & 0.004 & 1.61 & $\begin{array}{l}(1.14 \\
2.27)\end{array}$ & 0.007 \\
\hline Gastrointestinal & Gallstones & FinnGen & 1.87 & $\begin{array}{l}(1.58 \\
2.23)\end{array}$ & $\begin{array}{l}7 . \mathrm{E}- \\
10\end{array}$ & 1.99 & $\begin{array}{l}(1.78 \\
2.22)\end{array}$ & $\begin{array}{l}1 . \mathrm{E}- \\
30\end{array}$ & 1.37 & $\begin{array}{l}(0.86 \\
2.19)\end{array}$ & 0.200 & 2.55 & $\begin{array}{l}(1.88 \\
3.45)\end{array}$ & $\begin{array}{l}9 . \mathrm{E}- \\
07\end{array}$ \\
\hline Gastrointestinal & $\begin{array}{l}\text { Gastro- } \\
\text { oesophageal } \\
\text { reflux disease }\end{array}$ & $\begin{array}{l}\text { Meta- } \\
\text { analysis }\end{array}$ & 1.15 & $\begin{array}{l}(1.05 \\
1.25)\end{array}$ & 0.002 & 1.48 & $\begin{array}{l}(1.00 \\
2.18)\end{array}$ & 0.051 & 1.16 & $\begin{array}{l}(0.96, \\
1.41)\end{array}$ & 0.119 & 1.26 & $\begin{array}{l}(0.99 \\
1.61)\end{array}$ & 0.062 \\
\hline Nervous & $\begin{array}{l}\text { Alzheimer's } \\
\text { disease }\end{array}$ & $\begin{array}{l}\text { Meta- } \\
\text { analysis }\end{array}$ & 0.98 & $\begin{array}{l}(0.85 \\
1.13)\end{array}$ & 0.791 & 0.99 & $\begin{array}{l}(0.96, \\
1.03)\end{array}$ & 0.697 & 1.00 & $\begin{array}{l}(0.92, \\
1.08)\end{array}$ & 0.939 & 1.02 & $\begin{array}{l}(0.98 \\
1.07)\end{array}$ & 0.335 \\
\hline Nervous & Depression & $\begin{array}{l}\text { Meta- } \\
\text { analysis }\end{array}$ & 1.12 & $\begin{array}{l}(0.98 \\
1.27)\end{array}$ & 0.092 & 1.19 & $\begin{array}{l}(1.11, \\
1.28)^{\prime}\end{array}$ & $\begin{array}{l}\text { 1.E- } \\
06\end{array}$ & 1.20 & $\begin{array}{l}(0.98 \\
1.48)\end{array}$ & 0.074 & 1.02 & $\begin{array}{l}(0.81 \\
1.30)\end{array}$ & 0.855 \\
\hline Nervous & Multiple sclerosis & FinnGen & 0.81 & $\begin{array}{l}(0.47 \\
1.40)\end{array}$ & 0.443 & 0.85 & $\begin{array}{l}(0.58 \\
1.25)\end{array}$ & 0.407 & 1.53 & $\begin{array}{l}(0.38 \\
6.20)\end{array}$ & 0.559 & 0.62 & $\begin{array}{l}(0.24, \\
1.59)\end{array}$ & 0.332 \\
\hline Nervous & $\begin{array}{l}\text { Parkinson's } \\
\text { disease }\end{array}$ & $\begin{array}{l}\text { Meta- } \\
\text { analysis }\end{array}$ & 0.96 & $\begin{array}{l}(0.77 \\
1.19)^{\prime}\end{array}$ & 0.704 & 0.88 & $\begin{array}{l}(0.63, \\
1.24)\end{array}$ & 0.472 & 1.35 & $\begin{array}{l}(0.87 \\
2.08)\end{array}$ & 0.176 & 0.83 & $\begin{array}{l}(0.44 \\
1.55)\end{array}$ & 0.551 \\
\hline Integumentary & Psoriasis & $\begin{array}{l}\text { Meta- } \\
\text { analysis }\end{array}$ & 1.62 & $\begin{array}{l}(1.20 \\
2.19)\end{array}$ & 0.001 & 1.78 & $\begin{array}{l}(1.54, \\
2.05)\end{array}$ & $\begin{array}{l}3 . E- \\
15\end{array}$ & 1.20 & $\begin{array}{l}(0.70 \\
2.06)\end{array}$ & 0.514 & 2.11 & $\begin{array}{l}(1.49 \\
2.99)\end{array}$ & $\begin{array}{l}3 . E- \\
05\end{array}$ \\
\hline Respiratory & $\begin{array}{l}\text { Adult-onset } \\
\text { asthma }\end{array}$ & $\begin{array}{l}\text { Meta- } \\
\text { analysis }\end{array}$ & 1.25 & $\begin{array}{l}(1.03, \\
1.52)\end{array}$ & 0.022 & 1.43 & $\begin{array}{l}(1.25, \\
1.63)\end{array}$ & $\begin{array}{l}3 . \mathrm{E}- \\
07\end{array}$ & 1.14 & $\begin{array}{l}(0.88 \\
1.49)\end{array}$ & 0.319 & 1.34 & $\begin{array}{l}(0.97 \\
1.87)^{\prime}\end{array}$ & 0.080 \\
\hline Cancer & $\begin{array}{l}\text { Barrett's } \\
\text { oesophagus }\end{array}$ & FinnGen & 1.29 & $\begin{array}{l}(0.55 \\
3.02)\end{array}$ & 0.558 & 1.42 & $\begin{array}{l}(0.79 \\
2.54)^{\prime}\end{array}$ & 0.242 & 3.16 & $\begin{array}{l}(0.39 \\
25.47)\end{array}$ & 0.288 & 0.62 & $\begin{array}{l}(0.14 \\
2.65)\end{array}$ & 0.522 \\
\hline Cancer & Breast cancer & $\begin{array}{l}\text { Meta- } \\
\text { analysis }\end{array}$ & 0.60 & $\begin{array}{l}(0.51 \\
0.70)\end{array}$ & $\begin{array}{l}4 . \mathrm{E}- \\
10\end{array}$ & 0.84 & $\begin{array}{l}(0.71, \\
0.98)^{\prime}\end{array}$ & 0.032 & 1.12 & $\begin{array}{l}(0.64, \\
1.94)\end{array}$ & 0.689 & 0.52 & $\begin{array}{l}(0.39 \\
0.68)\end{array}$ & $\begin{array}{l}4 . E- \\
06\end{array}$ \\
\hline Cancer & Cancer myeloma & FinnGen & 1.60 & $(0.76$ & 0.221 & 1.43 & (0.85, & 0.179 & 1.96 & $(0.25$ & 0.529 & 1.33 & $(0.30$ & 0.710 \\
\hline
\end{tabular}




\begin{tabular}{|c|c|c|c|c|c|c|c|c|c|c|c|c|c|c|}
\hline & & & & $3.40)$ & & & 2.39) & & & 15.59) & & & 5.99) & \\
\hline Cancer & Colorectal cancer & $\begin{array}{l}\text { Meta- } \\
\text { analysis }\end{array}$ & 1.09 & $\begin{array}{l}(0.89, \\
1.35)^{\prime}\end{array}$ & 0.408 & 0.96 & $\begin{array}{l}(0.77, \\
1.19)^{\prime}\end{array}$ & 0.697 & 0.67 & $\begin{array}{l}(0.52, \\
0.85)\end{array}$ & 0.001 & 1.20 & $\begin{array}{l}(0.97, \\
1.50)\end{array}$ & 0.094 \\
\hline Cancer & $\begin{array}{l}\text { Endometrial } \\
\text { cancer }\end{array}$ & $\begin{array}{l}\text { Meta- } \\
\text { analysis }\end{array}$ & 1.82 & $\begin{array}{l}(1.26, \\
2.63)^{\prime}\end{array}$ & 0.002 & 1.36 & $\begin{array}{l}(0.86, \\
2.16)^{\prime}\end{array}$ & 0.190 & 0.93 & $\begin{array}{l}(0.53, \\
1.63)\end{array}$ & 0.802 & 1.48 & $\begin{array}{l}(0.44, \\
4.98)\end{array}$ & 0.527 \\
\hline Cancer & Lung cancer & FinnGen & 1.21 & $\begin{array}{l}(0.75, \\
1.96)\end{array}$ & 0.444 & 1.33 & $\begin{array}{l}(1.00, \\
1.77)\end{array}$ & 0.051 & 0.64 & $\begin{array}{l}(0.23, \\
1.78)\end{array}$ & 0.401 & 1.36 & $\begin{array}{l}(0.65, \\
2.84)\end{array}$ & 0.426 \\
\hline Cancer & Meningioma & FinnGen & 0.62 & $\begin{array}{l}(0.36, \\
1.06)\end{array}$ & 0.085 & 1.01 & $\begin{array}{l}(0.71, \\
1.43)^{\prime}\end{array}$ & 0.967 & 1.06 & $\begin{array}{l}(0.31, \\
3.61)\end{array}$ & 0.928 & 0.36 & $\begin{array}{l}(0.15, \\
0.86)\end{array}$ & 0.028 \\
\hline Cancer & Ovarian cancer & $\begin{array}{l}\text { Meta- } \\
\text { analysis }\end{array}$ & 1.15 & $\begin{array}{l}(0.72, \\
1.85)\end{array}$ & 0.562 & 1.16 & $\begin{array}{l}(0.69, \\
1.93)\end{array}$ & 0.579 & 0.35 & $\begin{array}{l}(0.18, \\
0.70)\end{array}$ & 0.003 & 1.26 & $\begin{array}{l}(0.80, \\
1.99)^{\prime}\end{array}$ & 0.315 \\
\hline Cancer & Pancreatic cancer & FinnGen & 1.39 & $\begin{array}{l}(0.67, \\
2.88)^{\prime}\end{array}$ & 0.376 & 1.25 & $\begin{array}{l}(0.79, \\
1.97)^{\prime}\end{array}$ & 0.345 & 3.30 & $\begin{array}{l}(0.50, \\
21.83)\end{array}$ & 0.224 & 1.45 & $\begin{array}{l}(0.45, \\
4.61)^{\prime}\end{array}$ & 0.536 \\
\hline Cancer & Prostate cancer & $\begin{array}{l}\text { Meta- } \\
\text { analysis }\end{array}$ & 0.91 & $\begin{array}{l}(0.81, \\
1.03)^{\prime}\end{array}$ & 0.135 & 0.90 & $\begin{array}{l}(0.83, \\
0.97)\end{array}$ & 0.006 & 0.97 & $\begin{array}{l}(0.79, \\
1.19)^{\prime}\end{array}$ & 0.772 & 0.94 & $\begin{array}{l}(0.77, \\
1.15)^{\prime}\end{array}$ & 0.565 \\
\hline Cancer & Renal cancer & $\begin{array}{l}\text { Meta- } \\
\text { analysis }\end{array}$ & 1.47 & $\begin{array}{l}(1.12, \\
1.92)\end{array}$ & 0.005 & 1.23 & $\begin{array}{l}(0.94, \\
1.60)\end{array}$ & 0.126 & 0.94 & $\begin{array}{l}(0.33, \\
2.72)\end{array}$ & 0.910 & 1.72 & $\begin{array}{l}(1.18, \\
2.51)\end{array}$ & 0.005 \\
\hline Cancer & Thyroid cancer & FinnGen & 0.90 & $\begin{array}{l}(0.52, \\
1.56)\end{array}$ & 0.719 & 0.73 & $\begin{array}{l}(0.51, \\
1.06)^{\prime}\end{array}$ & 0.103 & 0.91 & $\begin{array}{l}(0.24, \\
3.40)\end{array}$ & 0.888 & 1.09 & $\begin{array}{l}(0.42, \\
2.86)\end{array}$ & 0.859 \\
\hline
\end{tabular}

\section{Figures}

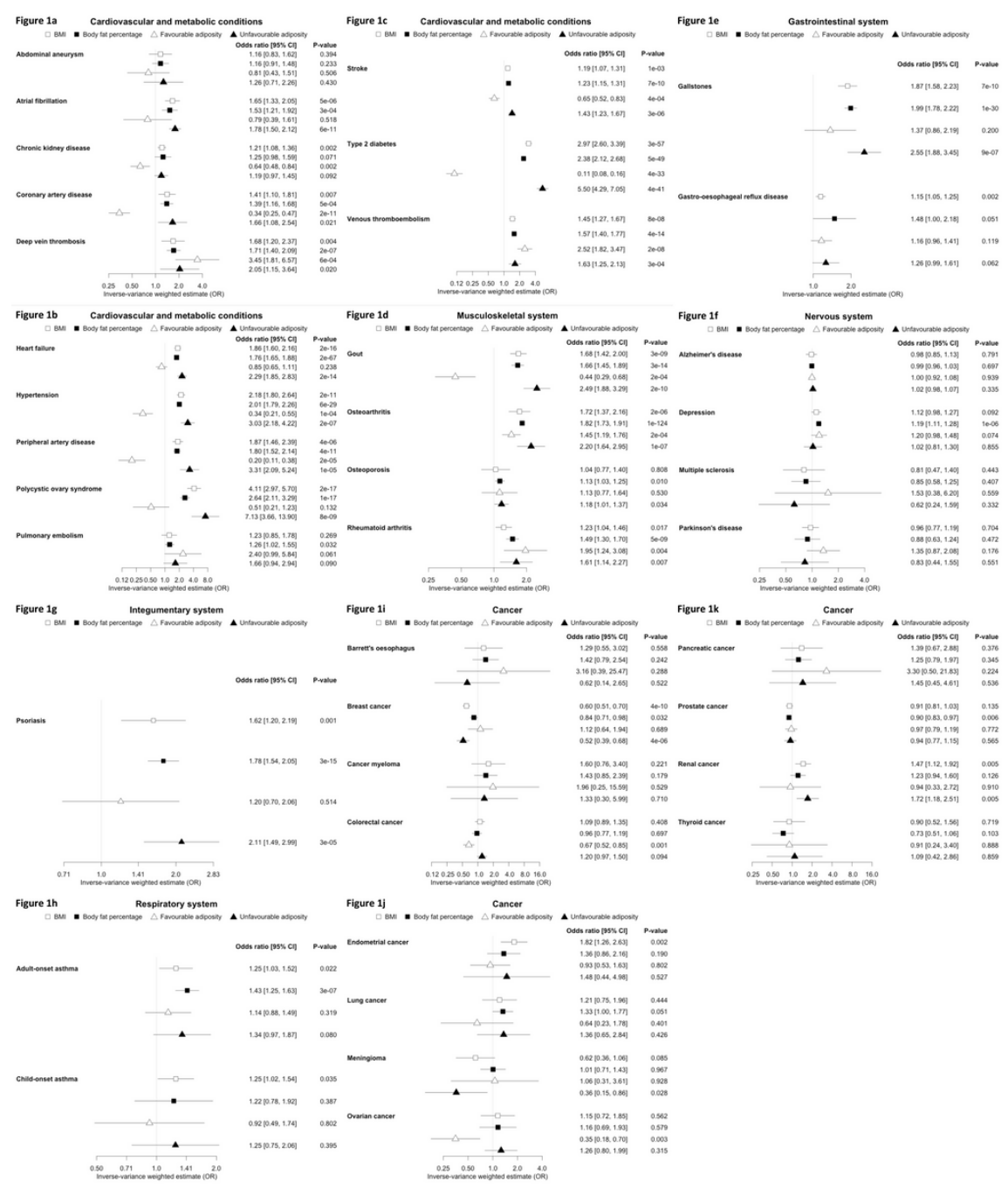

Figure 1 
The inverse-variance weighted (IVW) two-sample MR analysis/meta-analysis of published GWAS and/or FinnGen for body mass index (BMI), body fat percentage, "favourable adiposity" (FA) and "unfavourable adiposity" (UFA) clusters for disease outcomes grouped into (a-c) cardiovascular and metabolic conditions; (d) musculoskeletal system; (e) gastrointestinal system; (f) nervous system; (g) integumentary system; (h) respiratory system; and (i-k) cancer. The error bars represent the $95 \%$ confidence intervals of the IVW estimates in odds ratio per standard deviation change in genetically determined BMI, body fat percentage, FA and UFA.

\section{Supplementary Files}

This is a list of supplementary files associated with this preprint. Click to download.

- FAuncouplingsupplementary20210705.doc

- UncouplingSupplementaryFigures.pdf 